Nature

December 2019, Volume 576 Issue 7786 Pages 257-261

https://doi.org/10.1038/s41586-019-1796-9

https://archimer.ifremer.fr/doc/00593/70556/

\title{
Global satellite-observed daily vertical migrations of ocean animals
}

Behrenfeld Michael J. 1, ${ }^{*}$, Gaube Peter ${ }^{2}$, Della Penna Alice 2, 3, O'malley Robert T. ${ }^{1}$, Burt William J. 4, 5 , Hu Yongxiang ${ }^{6}$, Bontempi Paula S. ${ }^{7}$, Steinberg Deborah K. ${ }^{8}$, Boss Emmanuel S. ${ }^{9}$, Siegel David A. ${ }^{10,11}$, Hostetler Chris A. ${ }^{6,12}$, Tortell Philippe D. ${ }^{4}$, Doney Scott C. ${ }^{13}$

${ }^{1}$ Department of Botany and Plant Pathology, Oregon State University, Corvallis, OR, USA

${ }^{2}$ Applied Physics Laboratory, Air-Sea Interaction and Remote Sensing Department, University of Washington, Seattle, WA, USA

${ }^{3}$ Laboratoire des Sciences de l'Environnement Marin (LEMAR), UMR 6539 CNRS-Ifremer-IRD-UBOInstitut Universitaire Européen de la Mer (IUEM), Plouzané, France

${ }^{4}$ Earth, Ocean and Atmospheric Sciences, University of British Columbia, Vancouver, British Columbia, Canada

${ }^{5}$ College of Fisheries and Ocean Sciences, University of Alaska Fairbanks, Fairbanks, AK, USA

${ }^{6}$ NASA Langley Research Center, Hampton, VA, USA

${ }^{7}$ Earth Science Division, Science Mission Directorate, National Aeronautics and Space Administration Headquarters, Washington, DC, USA

${ }^{8}$ Virginia Institute of Marine Science, College of William \& Mary, Gloucester Point, VA, USA

${ }^{9}$ School of Marine Sciences, University of Maine, Orono, ME, USA

${ }^{10}$ Earth Research Institute, University of California Santa Barbara, Santa Barbara, CA, USA

${ }^{11}$ Department of Geography, University of California Santa Barbara, Santa Barbara, CA, USA

${ }^{12}$ Botany Department, University of British Columbia, Vancouver, British Columbia, Canada

${ }^{13}$ Department of Environmental Sciences, University of Virginia, Charlottesville, VA, USA

*Corresponding author : Michael J. Behrenfeld, email address : mib@science.oregonstate.edu

\begin{abstract}
:
Every night across the world's oceans, numerous marine animals arrive at the surface of the ocean to feed on plankton after an upward migration of hundreds of metres. Just before sunrise, this migration is reversed and the animals return to their daytime residence in the dark mesopelagic zone (at a depth of $200-1,000 \mathrm{~m}$ ). This daily excursion, referred to as diel vertical migration (DVM), is thought of primarily as an adaptation to avoid visual predators in the sunlit surface layer1,2 and was first recorded using ship-net hauls nearly 200 years ago3. Nowadays, DVMs are routinely recorded by ship-mounted acoustic systems (for example, acoustic Doppler current profilers). These data show that night-time arrival and departure times are highly conserved across ocean regions4 and that daytime descent depths increase with water clarity4,5, indicating that animals have faster swimming speeds in clearer waters4. However, after decades of acoustic measurements, vast ocean areas remain unsampled and places for which data are available typically provide information for only a few months, resulting in an incomplete understanding of DVMs. Addressing this issue is important, because DVMs have a crucial role in global ocean biogeochemistry. Night-time feeding at the surface and daytime metabolism of this food at depth provide
\end{abstract}


an efficient pathway for carbon and nutrient export6,7,8. Here we use observations from a satellitemounted light-detection-and-ranging (lidar) instrument to describe global distributions of an optical signal from DVM animals that arrive in the surface ocean at night. Our findings reveal that these animals generally constitute a greater fraction of total plankton abundance in the clear subtropical gyres, consistent with the idea that the avoidance of visual predators is an important life strategy in these regions. Total DVM biomass, on the other hand, is higher in more productive regions in which the availability of food is increased. Furthermore, the 10-year satellite record reveals significant temporal trends in DVM biomass and correlated variations in DVM biomass and surface productivity. These results provide a detailed view of DVM activities globally and a path for refining the quantification of their biogeochemical importance. 
67 For decades, airplane-mounted light-detection-and-ranging (lidar) instruments have used the

backscattering of light $(b b p)$ from phytoplankton, zooplankton, and small fish to locally map the distribution of these organisms in the water column ${ }^{9-11}$. Unlike passive ocean sensors that measure reflected sunlight, lidar uses lasers as a light source and thus has the capacity to measure marine organisms both day and night. When DVM animals are prominent, their nocturnal invasion of the surface ocean is expected to increase $b b p$ at night compared to what it would be in their absence. Five ship-based examples ${ }^{12}$ of this DVM signature are shown in figure 1a, where the animal signals contribute $7 \%$ to $28 \%$ of total nighttime $b b p$. These signals appear as large spikes in this record because DVM animals are 'bright' targets compared to the phytoplankton and other suspended particles constituting the much lower $b b p$ baseline ${ }^{13}$ [purple line in Fig. 1a], but the animals are also rarer and only occasionally pass through the small sample volume $(\sim 2 \mathrm{ml})$ of the ship's $b b p$ instrument. In contrast, a lidar with a much larger sampling volume can effectively capture the signal of all scattering components with every measurement. The satellite Cloud-Aerosol Lidar with Orthogonal Polarization (CALIOP) sensor has been conducting such measurements for over a decade ${ }^{14-15}$ [Methods] and its $b b p$ retrievals provide an opportunity to decipher global patterns in vertically migrating animals. 
84 The laser footprint of CALIOP has a diameter of $100 \mathrm{~m}$ at the ocean surface and a vertical

85 sampling depth of $22 \mathrm{~m}$ in water. What this means is that each CALIOP measurement integrates

86 the $b b p$ signal from a water volume of $1.73 \times 10^{5} \mathrm{~m}^{3}$, which is $\sim 5 \times 10^{6}$ greater than the entire water

87 volume measured over a given night in the field data shown in figure 1a. CALIOP's large

88 sampling volume thus ensures that each retrieved $b b p$ value encompasses both the animals and

89 suspended cells and particles in the surface layer. CALIOP is a polar orbiting sensor that

90 conducts daytime and nighttime ( 1:40 p.m. and a.m. local time, respectively) near-nadir

91 backscattering measurements along its orbit track at a sampling frequency equivalent to every

$92330 \mathrm{~m}$ on the ground. A slightly precessing orbit with a 16-day repeat cycle provides global $b b p$

93 coverage, but ground tracks oriented in opposite directions on the daylight and dark sides of the

94 Earth mean that day and night $b b p$ samples are rarely spatially coincident within a given $24 \mathrm{~h}$

95 period [Extended Data Fig. 1, Supplementary Discussion]. The global signature of DVM

96 animals was therefore investigated by creating $2^{\circ}$ latitude by $2^{\circ}$ longitude binned monthly

97 CALIOP daytime $\left(b b p^{d a y}\right)$ and nighttime $\left(b b p^{\text {night }}\right)$ values of $b b p$.

98

99 In the absence of any DVM, the biomass-normalized $b b p$ difference ratio:

100

$$
\Delta b b p=\left(b b p^{n i g h t}-b b p^{d a y}\right) / b b p^{d a y}
$$

101 is expected to yield a negative value for the measurement times of CALIOP [vertical red dotted 102 lines in Fig. 1b]. This is because daytime increases in phytoplankton cell size and organic 103 carbon content and nighttime cell division and metabolism ${ }^{16-18}$ create a baseline diel cycle in 104 biomass-normalized $b b p$ with an afternoon maximum and nighttime minimum [Fig. 1b] ${ }^{19}$. The 105 presence of DVM animals increases $b b p^{\text {night }}[$ Fig. 1a] and therefore causes $\Delta b b p$ to become less 106 negative than the phytoplankton-only signal, or even positive if the migrators are sufficiently 
107 abundant. Thus, phytoplankton and DVM animals together determine $\Delta b b p$ [Fig. 1c], where the 108 magnitude and sign of $\Delta b b p$ is an index of the DVM signal strength relative to that of the 109 phytoplankton.

111 The 2008 to 2017 CALIOP record reveals broad, spatially-coherent patterns in climatological 112 average $\Delta b b p$ at tropical and subtropical latitudes [equatorward of the yellow/black lines in Fig. 113 2] where plankton populations are relatively stable in time due to the water column being 114 permanently stratified within the euphotic zone (referred to hereafter as the permanently 115 stratified ocean; PSO). These eight broad features [black outlines in Fig. 2] correspond to the 116 seasonally-varying boundaries of the North Pacific (NPSG), South Pacific (SPSG), North 117 Atlantic (NASG), South Atlantic (SASG), and South Indian (SISG) Subtropical Gyres and the 118 higher-nutrient Tropical Pacific (TP) and North Tropical (NTA) and South Tropical (STA) 119 Atlantic [Fig. 2, 3a, Extended Data Fig. 2]. Within these regions, $\Delta b b p$ values are persistently 120 positive in the NPSG, persistently negative in the TP and NTA, and strongly seasonal in the 121 NASG, STA, and all three Pacific areas [Extended Data Fig. 3]. In the high-latitude seasonal 122 seas [poleward of the yellow/black line in Fig. 2], the CALIOP record reveals large 123 climatological average values for $\Delta b b p$. However, persistent cloud cover and small-scale spatio124 temporal variations in plankton populations in these regions cause within-bin mismatches in $125 b b p^{d a y}$ and $b b p^{n i g h t}$ data to yield significant bin-to-bin variability in $\Delta b b p$ [Supplementary 126 Discussion]. From this point forward, therefore, our analysis primarily focuses on the eight 127 regions of the PSO. 
129 If variability in $\Delta b b p$ is largely a reflection of DVM strength rather than changes in the

130 phytoplankton cycle, then results shown in figure 2 suggest significant regional differences in the

131 relative nighttime abundance of these animals. To test this DVM-basis of the regional patterns,

132 we compared CALIOP data to historical field ADCP observations of paired day $\left(I_{d B^{d a y}}\right)$ and night

$133\left(I_{d B^{n g h t}}\right)$ acoustic backscatter. Due to the sparsity of such data, it was necessary to aggregate 32

134 years (1985 to 2017) of field measurements into monthly $5^{\circ}$ latitude by $5^{\circ}$ longitude bins to

135 achieve even reasonable global coverage. [Methods]. We then calculated median values of the

136 normalized difference ratio:

$$
\triangle B_{A D C P}=\left(I_{d B^{n i g h t}}-I_{d B^{d a y}}\right) / I_{d B^{d a y}} .
$$

138 CALIOP $b b p$ data were then reaggregated into equivalent $5^{\circ} \times 5^{\circ}$ bins and regional median 139 values of $\triangle b b p$ were calculated using only those calendar months and bins for which ADCP data 140 were available. Comparison of $\triangle B_{A D C P}$ and $\triangle b b p$ for all bins within our eight PSO regions

141 yielded a statistically significant relationship $(\mathrm{p}=0.001, \mathrm{n}=331)$ [Fig. 3b, red line] with a slope 142 very similar to that calculated from regionally-averaged values for the six regions where ADCP 143 data identify a significant DVM signal [Fig. 3b, dashed line] [Supplementary Discussion]. In 144 other words, the ADCP and lidar data sets both indicate DVM animals constitute a greater 145 fraction of nighttime plankton communities in the optically-clear subtropical gyres that are most 146 advantageous to visual predators. Interestingly, the regionally-averaged data for the SISG and 147 SASG deviate from the other PSO regions [Fig. 3b]. The reason for this difference is unknown. 148 These are the only two regions where $\triangle B_{A D C P}$ is near zero, suggesting either few DVM animals 149 or that the influx of nighttime DVM animals is compensated by reverse-DVM animals leaving 150 the surface layer ${ }^{20}$. CALIOP data, in contrast, suggest a moderate DVM signal in the SISG and 151 SASG [Fig. 3b]. Perhaps the discrepancy in these two regions is simply due to poor ADCP 
152 coverage (typically one day-night observation per $5^{\circ} \times 5^{\circ}$ bin for the 32 year field record).

153 However, it is also noteworthy that all of the ADCP data in the SASG and all but eight

154 observations in the SISG predate the CALIOP mission, so a temporal change in DVM

155 populations cannot be ruled out.

156

157 Day and night zooplankton net tows provide quantitative field measurements of DVM biomass, 158 but these labor-intensive measurements are rarely collected at regular intervals over long periods.

159 Two exceptions in the PSO are the sustained records at the Hawaii Ocean Time-series (HOT) 160 site $\left(22^{\circ} 45^{\prime} \mathrm{N}, 158^{\circ} \mathrm{W}\right)^{21}$ and the Bermuda Atlantic Time Series (BATS) site $\left(31^{\circ} 40^{\circ} \mathrm{N}, 64^{\circ}\right.$

$\left.16110^{\prime} \mathrm{W}\right)^{22}$ [yellow stars in Fig. 3a]. Despite considerable interannual variability, significant $(\mathrm{p}<$ $1620.01)$ seasonal cycles in DVM biomass $\left(\mathrm{g}\right.$ dry weight $\mathrm{m}^{-2}$ ) are observed at these locations. For 163 the CALIOP bin centered on the HOT site, the seasonal cycle in $\Delta b b p$ from January through 164 November is significantly correlated $\left(\mathrm{r}^{2}=0.44, \mathrm{p}=0.03\right)$ with field observations [Fig. 3c]. 165 Likewise, $\Delta b b p$ for the CALIOP bin centered on the BATS site exhibits a two-peaked seasonal 166 cycle that is well correlated with field observations from August through June $\left(r^{2}=0.42, p=\right.$ 167 0.03) [Fig. 3d]. These results are particularly noteworthy given the temporal and spatial contrast 168 between data sets $\left(\mathrm{CALIOP}=2^{\circ}\right.$ latitude $\mathrm{x} 2^{\circ}$ longitude bins from $2008-2017$; zooplankton nets 169 at HOT and BATS from $1994-2005^{21}$ and $1994-2017$, respectively). Thus, correspondence 170 between $\Delta b b p$ (which includes DVM animals, surface-resident organisms, and suspended 171 particles) and animal-specific $\mathrm{ADCP}^{22}$ [Fig. 3b] and net measurements [Fig. 3c,d] gives 172 confidence to the DVM signal detected by CALIOP. 
174 The biomass-normalized $\Delta b b p$ property reflects the relative strength of the DVM signal, whereas

175 DVM biomass $\left(D V M_{C A L I O P}\right)$ is more quantitatively related to the simple difference, $b b p^{\text {night }}$ -

$176 b b p^{d a y}$. We estimated DVMCALIOP from this difference as:

$$
D V M_{C A L I O P}=a\left(b b p^{n i g h t}-c b b p^{d a y}\right)
$$

178 where $a$ is an empirical conversion factor between backscattering $\left(\mathrm{m}^{-1}\right)$ and biomass $\left(\mathrm{g} \mathrm{m}^{-2}\right)$

179 determined from BATS and CALIOP data and $c$ accounts for night-day $b b p$ differences from 180 growth rate and day length dependent variations in the phytoplankton diel cycle [Methods].

181 Application of (3) to the CALIOP record yields a global distribution in DVMCALIOP [Fig. 4a] that 182 differs markedly from $\triangle b b p$ [Fig. 2]. In particular, DVMCALIOP is generally low in the subtropical 183 gyres and high in the nutrient-enriched tropical regions. Thus, while the relative contribution of 184 DVM animals to nighttime plankton communities is higher in clearer waters [Fig. 2], total DVM 185 biomass is greater in more productive regions where food availability is enhanced [Fig. 4a].

186 Indeed, annual average DVMCALIOP for our PSO regions is highly correlated with passive ocean 187 color based estimates of net primary production $\left(r^{2}=0.80, p=0.002\right)$ [Fig. 4b, Methods].

188 Results for the high-latitude northern and southern regions are also consistent with this finding 189 [Fig. 4b]. Importantly, an increase in phytoplankton production yields a less than proportional 190 increase in DVMCALIOP, as might be expected for migrating animals that may be multiple trophic 191 levels removed from the phytoplankton. Consequently, the night-day difference in $b b p$ caused 192 by the phytoplankton diel cycle [Fig. 1b] generally increases more rapidly than the DVM signal 193 as productivity increases, resulting in negative $\Delta b b p$ values in productive tropical regions [Fig. 194 2]. 
Evidence of long-term changes in zooplankton populations, often linked to climate oscillations,

197 has emerged from field time-series studies ${ }^{22-27}$. At the HOT site, field-measured DVM zooplankton biomass increased on average $12.4 \mathrm{mg} \mathrm{m}^{-2} \mathrm{y}^{-1}\left(38 \%\right.$ decade $\left.^{-1}\right)$ between 1994 and $1992005(\mathrm{p}=0.04)^{21}$. The DVMCALIOP record indicates that this trend continued $(\mathrm{p}=0.05)$ at a rate of $23 \%$ decade $^{-1}$ from 2008 to 2017 [Fig. 4c, red star]. At BATS, an overall increasing trend of $7.4 \mathrm{mg} \mathrm{m}^{-2} \mathrm{y}^{-1}\left(54 \%\right.$ decade $\left.^{-1}\right)$ was reported for field observations from 1994 to $2011(\mathrm{p}<$ $0.01)^{22}$. Expanding this data set to 2017 and re-evaluating, we find DVM biomass increased $63 \%$ decade $^{-1}$ from 1994 to $2007(p=0.01)$ and then decreased $28 \%$ decade $^{-1}$ from 2008 to 2017 $204(\mathrm{p}=0.04)$. For this latter period, DVMCALIOP data similarly suggest a decreasing trend $(9 \%$ 205 decade $\left.{ }^{-1} ; \mathrm{p}>0.1\right)$ for the $2^{\circ} \times 2^{\circ}$ bin encompassing the BATS site [Fig. 4c, blue star]. The global coverage provided by CALIOP now allows the evaluation of DVM biomass temporal trends to

207 be greatly expanded. For example, subdividing our eight PSO regions [Fig. 3a] into $6^{\circ} \times 6^{\circ}$ bins 208 and evaluating only those bins that remain within their respective regional boundaries throughout 209 the year [Extended Data Fig. 2] reveals decadal trends in DVMCALIOP with coherent geographical 210 patterns [Fig. 4c]. Specifically, a predominance of increasing DVM animal biomass is observed 211 in the NPSG, SPSG, SASG, and SISG, whereas decreasing DVM biomass is indicated across

212 much of the tropical regions and the NASG. Moreover, DVMCALIOP is positively correlated with 213 changes in phytoplankton production for most bins, but in the two tropical Atlantic regions the 214 correlations are counterintuitively inverse [Fig. 4c].

216 The power of a satellite lidar in studying marine animals lies in its unparalleled annual coverage 217 of the global ocean. By contrast, it was necessary here to compile $>30$ years of ADCP 218 measurements to create a single field test data set and, even then, spatial and temporal coverage 
219 is poor in many regions [Extended Data Fig. 4]. A challenge with satellite lidar data, however, is 220 that the measured night-day $b b p$ differences are not solely due to DVM animals, so continued 221 work is needed to refine descriptions of the non-DVM contributors [Methods, Supplementary 222 Discussion]. Further field data analyses (e.g., ADCP data, continuous plankton recorder survey 223 observations) and modeling ${ }^{28}$ are also needed to fully understand the causative ecological 224 processes underlying the spatial and temporal DVM patterns observed from space, while an 225 advanced satellite lidar with ocean profiling capabilities ${ }^{11}$ may contribute new insights on DVM 226 behaviors [Supplementary Discussion]. While there are clearly multiple new avenues to pursue 227 regarding the study DVM animals, results presented here provide a forward step in the global 228 exploration of this greatest animal migration on Earth.

229

230 1. Lampert, W. The adaptive significance of diel vertical migration of zooplankton. Funct. $231 \quad$ Ecol. 3, 21-27 (1989).

232

233 2. Hays, G. C. A review of the adaptive significance and ecosystem consequences of 234 zooplankton diel vertical migrations. Hydrobiol, 503, 163-170 (2003).

235

3. Cuvier, G. Le règne animal distribué d'après son organisation pour à l'histoire naturelle des animaux et d'introduction à l'anatomie compare. Deterville (1829).

4. Bianchi, D. \& Mislan, K.A.S. Global patterns of diel vertical migration times and velocities from acoustics data. Limnol. Oceanogr. 61, 353-364 (2015). 
242 5. Røstad, A., Kaartvedt, S. \& Aksnes, D.L. Light comfort zones of mesopelagic acoustic scattering layers in two contrasting optical environments. Deep Sea Res. I 113, 1-6 (2016).

6. Steinberg, D.K., Goldthwait, S.A. \& Hansell, D.A. Zooplankton vertical migration and the active transport of dissolved organic and inorganic nitrogen in the Sargasso Sea. Deep-Sea

248

249

250

7. Bianchi, D., Stock, C., Galbraith, E.D. \& Sarmiento, J.L. Diel vertical migration: Ecological Res. I 49, 1445-1461 (2002).

251 controls and impacts on the biological pump in a one-dimensional ocean model. Global Biogeochem. Cycl. 27, 478-491 (2013).

252

253

254

8. Steinberg, D.K. \& Landry, M.R. Zooplankton and the ocean carbon cycle. Ann. Rev. Mar. Sci. 9, 413-444 (2017).

255

256

257

9. Churnside, J.H., Wilson, J.J. \& Tatarskii, V.V. Lidar profiles of fish schools. Appl. Opt. 36, $6011-6020$ (1997).

258

10. Churnside, J.H. \& Thorne, R.E. Comparison of airborne lidar measurements with $420 \mathrm{kHz}$ echo-sounder measurements of zooplankton. Appl. Opt. 44, 5504-5511 (2005).

262 11. Hostetler, C.A., Behrenfeld, M.J., Hu, Y., Hair, J.W., Schulien, J.A. Spaceborne lidar in the study of marine systems. Ann. Rev. Mar. Sci. 10, 121-47 (2018). 
275

276

277

278

279

280

281

282

283

12. Burt, W. J., \& Tortell, P. D. Observations of zooplankton diel vertical migration from highresolution surface ocean optical measurements. Geophys. Res. Lett. 45, doi.org/10.1029/2018GL079992, (2018).

13. Briggs, N.T., Slade, W.H., Boss, E. \& Perry, M.J. Method for estimating mean particle size from high-frequency fluctuations in beam attenuation or scattering measurements. Appl. Opt. 52, 6710-6725 (2013).

14. Behrenfeld, M.J., et al. Space-based lidar measurements of global ocean carbon stocks. Geophys. Res. Lett. 40, 4355-4360 (2013).

15. Behrenfeld, M.J., et al. Annual boom-bust cycles of polar phytoplankton biomass revealed by space-based lidar. Nature Geosci. 10, 118-22 (2017).

16. Stramski, D., Shalapyonok, A., \& Reynolds, R. A. Optical characterization of the oceanic unicellular cyanobacterium Synechococcus grown under a day-night cycle in natural irradiance. J. Geophys. Res.-Ocean. 100, 13295-13307 (1995).

17. DuRand, M. D., Green, R. E., Sosik, H. M., \& Olson, R. J. Diel variations in optical properties of Micromonas pusilla (Prasinophyceae). J. Phycol. 38, 1132-1142 (2002).

18. Dall'Olmo, G., et al. Inferring phytoplankton carbon and eco-physiological rates from diel cycles of spectral particulate beam-attenuation coefficient. Biogeosci. 8, 3423-3439 (2011). 
289 19. Kheireddine, M. \& Antoine, D. Diel variability of the beam attenuation and backscattering 290 coefficients in the northwestern Mediterranean Sea (BOUSSOLE site). J. Geophys. Res.

$291 \quad$ Oceans, 119, 5465-5482 (2014).

292

293 20. Ohman, M.D., Frost, B.W. \& Cohen, E.B. Reverse diel vertical migration: an escape from 294 invertebrate predators. Science 220, 1404-1407 (1983).

295

296

21. Hannides, C.C.S, et al. Export stoichiometry and migrant-mediated flux of phosphorus in the 297 North Pacific Subtropical Gyre. Deep-Sea Res. I. 56, 73-88 (2009).

298 22. Steinberg, D.K., Lomas, M.W. \& Cope, J.S. Long-term increase in mesozooplankton

299 biomass in the Sargasso Sea: Linkage to climate and implications for food web dynamics and 300 biogeochemical cycling. Global Biogeochem. Cycl. 26, GB1004, 301 doi:10.1029/2010GB004026 (2012).

302

303 23. Richardson, A. J. In hot water: Zooplankton and climate change. ICES J. Mar. Sci. 65, 279$304 \quad 295(2008)$.

305

306

24. Beaugrand, G., Reid, P.C., Ibanez, F., Lindley, J.A. \& Edwards, M. Reorganization of North 307 Atlantic marine copepod biodiversity and climate. Science 296, 1692-1694 (2002).

308

25. Piontkovski, S.A. \& Castellani, C. Long-term declining trend of zooplankton biomass in the 310 Tropical Atlantic. Hydrobiol. 632, 365-370 (2009). 
312 26. Peterson, W. T. \& Schwing, F.B. A new climate regime in northeast Pacific ecosystems.

313 Geophys. Res. Lett. 30, 1896, doi:10.1029/2003GL017528 (2003).

314

315 27. Chiba, S.,Tadokoro, K.,Sugisaki, H. \& Saino, T. Effects of decadal climate change on 316 zooplankton over the last 50 years in the western subarctic North Pacific. Glob. Change

317 Biol. 12, 907-920 (2006).

318

319

28. Archibald, K., Siegel, D. A., \& Doney, S. C. Modeling the impact of zooplankton diel 320 vertical migration on the carbon export flux of the biological pump. Global Biogeochemical Cycles 33, 181- 199 doi: 10.1029/2018GB005983 (2019).

322

29. Behrenfeld, M.J., Boss, E., Siegel, D.A. \& Shea, D.M. Carbon-based ocean productivity and 324 phytoplankton physiology from space. Global Biogeochem. Cycles 19, GB1006, doi:10.1029/2004GB002299 (2005).

326

327 30. Siegel, D.A., et al. Regional to global assessments of phytoplankton dynamics from the 328 SeaWiFS mission. Rem. Sens. Env. 135, 77-91 (2013).

330 Supplementary Information is linked to the online version of the paper at 331 www.nature.com/nature. 
333 Acknowledgements: This work was supported by the National Aeronautics and Space

334 Administration's North Atlantic Aerosol and Marine Ecosystems Study (NAAMES) and EXport

335 Processes in the Ocean from RemoTe Sensing (EXPORTS) study. A. DP. was supported by the

336 Applied Physics Laboratory Science and Engineering Enrichment Development (SEED)

337 fellowship. This project received funding from the European Union's Horizon 2020 research and

338 innovation program under the Marie Sklodowska-Curie grant agreement No 749591.

339

340 Author Contributions: M.J.B. designed the study. M.J.B., P.G., A. DP, W.B, Y.H, and R.T.O.

341 processed data and analyzed results. M.J.B., P.G., A.DP, and R.T.O. prepared display items.

342 M.J.B. wrote the manuscript with contributions from all authors. 
Figure Legends

Figure 1. Marine animal and phytoplankton influences on day-to-night changes in particulate backscattering coefficients $(b b p)$ and the biomass-normalized difference ratio

( $\Delta \boldsymbol{b} \boldsymbol{b} \boldsymbol{p})$. (a) Ship-based time-series of $b b p$ showing nocturnal spikes associated with DVM animals and the general lack of these spikes during the day ${ }^{12}$ [Methods]. Black line $=$ complete $b b p$ record. Purple line $=$ de-spiked baseline $b b p$ record. (b) Typical diel cycle in $b b p$ due to phytoplankton ${ }^{19}$ [Methods]. Red dotted line $=$ daily equator crossing times of CALIOP. $(a-b)$ Black and white bars on x-axis indicate night and day, respectively. (c) Biomass-normalized difference ratios $(\Delta b b p)$ for ranges in DVM (x-axis) and phytoplankton (y-axis) contributions to day-to-night $b b p$ changes. For example, if the phytoplankton diel cycle corresponds (as in panel b) to a $15 \%$ day-to-night decrease in $b b p$ at the two CALIOP measurement times (horizontal white dashed arrow) and this decrease is countered by a 5\% increase in $b b p$ from DVM animals (vertical white dashed arrow), then $\Delta b b p$ will have a value of $-10 \%$ (color inside labeled white circle). Diagonal black lines correspond to the color bar range for the CALIOP observations shown in figure 2. Note that values on the y-axis encompass the range of values expected in the PSO [Supplementary Discussion, Extended Data Fig. 5].

Figure 2. Global climatological signal of vertically migrating animals quantified as the normalized difference ratio, $\Delta \boldsymbol{b b p}$. Data are $2^{\circ}$ latitude by $2^{\circ}$ longitude bin averages for the 2008 to 2017 CALIOP record. Yellow/black line = contour of annual average sea surface temperature of $15^{\circ} \mathrm{C}$, which effectively separates high-latitude seasonal seas from lower latitude

365 permanently stratified oceans. ${ }^{29-30}$ Heavy black lines separate major regions of the PSO, where 
the five subtropical gyres are defined by annual average surface chlorophyll concentrations of $\leq$ $0.08 \mathrm{mg} \mathrm{m}^{-3}$. Dark gray $=$ excluded pixels where water column depth $<1000 \mathrm{~m}$.

Figure 3. Comparison of CALIOP normalized difference ratios $(\Delta b b p)$ and field-based DVM measurements in the PSO. (a) Color-coded regions of the PSO from figure 2. Yellow stars $=$ locations of the Hawaii Ocean Time-series $(\mathrm{HOT})$ site and Bermuda Atlantic Time Series (BATS) site. (b) CALIOP $(\triangle b b p)$ versus field ADCP $\left(\triangle B_{A D C P}\right)$ normalized difference ratios. Red line $=$ two-sided least squares linear regression fit to all $5^{\circ}$ latitude $\mathrm{x} 5^{\circ}$ longitude bins within our eight PSO regions (slope $=0.42, \mathrm{~F}$ test $\mathrm{p}$ value $=0.001, \mathrm{n}=331$ independent geographical bins) [Supplementary Discussion]. Symbols $=$ regional average values of $\triangle b b p$ and $\triangle B_{A D C P}$, with standard error bars shown for each region ( $\mathrm{n}$ for each region $=19$ for SISG, 18 for SASG, 115 for TP, 16 for NASG, 23 for NTA, 59 for NPSG, 22 for STA, 59 for SPSG, 302 for Other) . Symbol colors identify region (labeled on right) and correspond to coloring in (a). For completeness, the average value for all PSO bins outside our eight primary regions is indicated by the white symbol. Numbers next to each symbol indicate the median number of days with ADCP data within the 32 year field record for the bins within a given region. Dashed line is two-sided least squares linear regression fit to regionally-averaged data for the $\mathrm{n}=$ six primary regions where $\triangle B_{A D C P}$ is significantly greater than zero (slope $=0.64, \mathrm{r}^{2}=0.55, \mathrm{p}=0.09$ ). (c) Average monthly field-measured $(1994-2005)^{21}$ migratory zooplankton biomass $\left(\mathrm{g} \mathrm{m}^{-2} \mathrm{dry}\right.$ weight) for the HOT site [Methods] ( $\mathrm{n}=112$ net haul samples) and CALIOP-measured $\Delta b b p$ (2008-2017) ( $\mathrm{n}=75$ monthly retrievals) for a $2^{\circ}$ latitude $\mathrm{x} 2^{\circ}$ longitude bin centered on the HOT site. Vertical lines indicate 1 standard deviation. Field and CALIOP data are offset on the x-axis 
388 by 6 days to separate standard deviation lines. (d) Same as in (c) except for field (1994-2017) (n $389=285$ net haul samples $)$ and CALIOP $(n=87$ monthly retrievals $)$ data at the BATS site.

391 Figure 4. CALIOP-based estimates of vertically migrating animal biomass (DVM $\left.M_{C A L I O P}\right)$

392 and temporal changes. (a) Annual average $D V M_{C A L I O P}\left(\mathrm{~g} \mathrm{~m}^{-2}\right.$ dry weight). Yellow-black and

393 heavy-black lines as in figure 2. (b) Relationship between annual average regional DVMCALIOP

394 and mixed layer net primary production $\left(N P P C b P M, \mathrm{mg} \mathrm{C} \mathrm{m}^{-3} \mathrm{~d}^{-1}\right)$ [Methods]. Solid line $=$ two-

395 sided least squares linear regression fit $\left(r^{2}=0.80, F\right.$ test $p$ value $=0.002, n=9$ geographic

396 regions) for the PSO regions, which are color-coded following figure 3a. Black symbols $=$ high-

397 latitude North Pacific (NP), North Atlantic (NA), and Southern Ocean (SO) (see panel c). Error

398 bars $=1$ standard deviation for annual values between 2008 and $2017(\mathrm{n}=111$ months per

399 geographic region). (c) Rate of change in $D V M_{C A L I O P}\left(\%\right.$ decade $\left.^{-1}\right)$ for $6^{0}$ latitude $\times 6^{0}$ longitude

400 bins for eight PSO regions and at the HOT and BATS sites (colored stars). Only bins that stay

401 within their respective regional boundaries throughout the year are shown [Extended Data Fig.

402 2]. Black dot in center of bin indicates trend is significant (two-sided least squares linear

403 regression, $\mathrm{F}$ test $\mathrm{p}$ value $\mathrm{p}<0.05, \mathrm{n}=111$ months per bin). Outlined bins exhibit a significant

404 (two-sided least squares linear regression, F test $\mathrm{p}$ value $<0.05, \mathrm{n}=111$ months per bin)

405 relationship between $D V M_{C A L I O P}$ and $N P P_{C b P M}$, with black and green outlines indicating positive 406 and negative correlations, respectively. 
Field data in Figure 1: Data shown in figure 1a provide five examples from the subarctic Pacific where DVM animals significantly increased ship-measured $b b p$ at night. Data are from

411 (12), which also provides full details on the study region, measurement system, data processing, 412 and uncertainty analyses. The phytoplankton diel cycle in $b b p$ shown in figure $1 \mathrm{~b}$ is from (19) 413 and is normalized to 1 at the nighttime minimum [Supplementary Discussion].

415 CALIOP data: CALIOP is the primary instrument on the Cloud-Aerosol Lidar and Infrared 416 Pathfinder Satellite Observation (CALIPSO) platform, which was launched in 2006 (31).

417 CALIOP measures the total time-dependent return of a pulsed laser output at $1064 \mathrm{~nm}$ and both 418 the co-polarized and cross-polarized return of a $532 \mathrm{~nm}$ laser output. The current study is based 419 on night and day differences in the cross-polarized return at $532 \mathrm{~nm} . b b p$ values (available at 420 http://www.science.oregonstate.edu/ocean.productivity/) were calculated from this signal 421 following (15), except that $b b p$ at $532 \mathrm{~nm}$ was not converted to $b b p$ at $440 \mathrm{~nm}$ as in the earlier 422 study. For (15), $30^{\circ}$ off-nadir CALIOP tilting maneuvers were conducted every two weeks 423 between 2015 and 2016 to collect ocean measurements with minimal surface backscatter from a 424 wide range of ocean environments. Removing molecular backscatter from the CALIOP parallel 425 channel and combining with data from the cross-polarized channel, we then derived particulate 426 backscatter depolarization ratios and compared these data to collocated MODIS diffuse 427 attenuation $\left(K_{d}\right)$ values. This analysis yielded a linear relationship between CALIOP 428 depolarization ratios and $K_{d}$ that was then used in (15) to directly retrieve $b b p$ values from 429 CALIOP without reliance on collocated MODIS observations. This same approach was used for 
430 the current study. However, we also further evaluated the relationship between particulate

431 depolarization ratios and $K_{d}$ at $532 \mathrm{~nm}$ using an extensive open ocean airborne lidar data set

432 compiled from the 2012 Azores campaign ${ }^{14}$, the Ship-Aircraft Bio-Optical Research (SABOR)

433 campaign, and three campaigns of the North Atlantic Aerosol and Marine Ecosystem Study

434 (NAAMES) $)^{32}$ (note, no airborne data were collected during the fourth NAAMES campaign due

435 to mechanical issues grounding the plane). This airborne-based analysis confirmed the earlier

436 CALIOP-MODIS finding of a linear relationship between depolarization ratios and $K_{d}$, with an

437 average depolarization: $K_{d}$ of $1.76 \mathrm{~m}$ and standard deviation of $0.19 \mathrm{~m}$. Finally, we calculated

$438 \quad b b p$ using a volume scattering function (VSF) at $180^{\circ}$ following $\mathrm{Lu}$ et al..$^{33}$ that was developed

439 using measurements from collocated CALIPSO and MODIS $531 \mathrm{~nm}$ data. This VSF is

440 consistent with scattering properties for particles in the phytoplankton size domain and it was

441 applied to both day and night CALIOP data. Organisms larger than phytoplankton, such as

442 DVM animals, will have a VSF with a somewhat lower efficiency in the backward direction and

443 enhanced efficiency in the forward direction. This difference is one factor [see also

444 Supplementary Discussion] influencing the relationship between the CALIOP-retrieved DVM

445 backscatter signal and the biomass of these animals, but it is encompassed in the field-based

446 scaling factor between CALIOP $b b p^{n i g h t}$ - $b b p^{d a y}$ data and zooplankton dry weight (see below).

448 CALIOP merges low gain and high gain data onboard to reduce data downlink. The onboard

449 gain ratio calculations fail when there are not enough data for both the low and high gain

450 channels, which can happen for nighttime cross polarization measurements. At the beginning of

451 the CALIPSO mission, there was an error in the default values of the gain ratios when the

452 onboard calculation fails. This issue rendered the nighttime cross polarization measurements 
453 unusable for ocean $b b p$ retrievals until the error was corrected in late 2007, which is why the

454 current study on night-day differences in $b b p$ was limited to the period of 2008 to 2017 . In

455 addition, Advanced Microwave Scanning Radiometer (AMSR) data were used to flag and omit

456 CALIOP retrievals made at wind speeds $\geq 9 \mathrm{~m} \mathrm{~s}^{-1}$ to avoid bubble contamination of the $b b p$

457 values. At wind speeds $<9 \mathrm{~m} \mathrm{~s}^{-1}$, we also applied a depolarization ratio threshold to remove

458 bubble-contaminated data based on statistical analysis from high wind conditions.

459

460 Calculation of $\boldsymbol{D V} \boldsymbol{M}_{\text {CALIOP: }}$ The biomass of DVM animals (DVMCALIOP) was estimated from

461 CALIOP-measured night-day differences in $b b p$, an estimate of the day-to-night change in $b b p$

462 due to the phytoplankton diel cycle alone [Fig. 1b], and a scaling factor between backscattering

463 and zooplankton dry weight.

464

465 The value of $b b p^{n i g h t}$ can be expanded into backscatter by DVM animals $\left(b b p^{D V M}\right)$ and

466 backscatter by phytoplankton and other non-migrating particles ( $\left.b b p^{\text {other }}\right)$ :

467

$$
b b p^{n i g h t}=b b p^{D V M}+b b p^{o t h e r} .
$$

468 The value of $b b p^{\text {other }}$ is equal to $b b p^{d a y}$ corrected for the phytoplankton-based change (c) in $b b p$

469 from day to night. Rearranging (4) and solving for $b b p^{D V M}$ yields:

$$
b b p^{D V M}=b b p^{n i g h t}-c b b p^{d a y} .
$$

471 A variety of factors may influence the value of $c$, including the daily division rate of the

472 phytoplankton population, the degree to which this division is synchronized around the day-night

473 cycle, the composition of the phytoplankton community ${ }^{34}$, and day length. Over much of the

474 PSO, phytoplankton populations are dominated by Prochlorococcus, Synechococcus, and

475 picoeukaryotics species, all of which generally synchronize cell division to the first half of the 
476 night ${ }^{35-39}$. We therefore focused on describing $c$ as a function of both division rate ( $\mu$; divisions

477 day $^{-1}$ ) and day length.

478

479 First, the dependence of $c$ on $\mu$ was determined from the laboratory study of DuRand and

480 Olson $^{34}$ and is described by [Supplementary Discussion; Extended Data Fig. 5a]:$$
c_{1}=0.929-0.122 \mu \text {, }
$$

482 where the term -0.122 has units of days division ${ }^{-1}$. Equation 6 was applied to MODIS passive

483 ocean color based estimates of $\mu$ calculated for the 2008 to 2017 period (see below). Second, the

484 dependence of $c$ on day length exists because a change in day length causes the two CALIOP

485 sampling points (determined by its fixed orbit) to line up differently with the phytoplankton diel

486 cycle. For the range of day lengths encountered across the PSO, this day length $(d l)$ dependence

487 is described by [Supplementary Discussion; Extended Data Fig. 5b]:

488

$$
c_{2}=0.986+0.0012 d l
$$

489 where $d l(\mathrm{~h})$ is known precisely for each CALIOP pixel based on date and latitude and the term

$490 \quad 0.0012$ has units of $h^{-1}$.

491

492 Monthly DVM zooplankton dry weight data are available at the BATS site over the 2008 to 2017

493 CALIOP era. Comparison of these field data to monthly $b b p^{D V M}$ values calculated from

494 equations (5) through (7) for the $2^{\circ}$ latitude by $2^{\circ}$ longitude CALIOP bin centered on the BATS

495 site yields an average scaling factor between $b b p^{D V M}$ and DVM biomass of $1596 \mathrm{~g} \mathrm{~m}^{-1}$

496 [Supplementary Discussion]. Applying this conversion factor gives the following expression for

497 DVMCALIOP:

498

$$
D V M_{C A L I O P}=1596\left(b b p^{n i g h t}-c_{1} c_{2} b b p^{d a y}\right) .
$$


In figures $3 \mathrm{c}$ and $3 \mathrm{~d}$, we compare HOT and BATS DVM zooplankton dry weight data to the

500 CALIOP-retrieved property, $\Delta b b p$, simply to maintain consistency with figure $3 b$

501 [Supplementary Discussion]. However and as stated in the main text, DVM biomass should be

502 quantitatively related to the simple difference, $b b p^{\text {night }}-b b p^{d a y}$. The reason the seasonal cycle in

$503 \Delta b b p$ corresponds to that of DVM biomass at HOT and BATS is that $b_{b p}{ }^{d a y}$ varies little over the

504 year at these two sites, making $\Delta b b p$ highly correlated $\left(\mathrm{r}^{2}>0.99, \mathrm{p}<0.001\right)$ with the simple

505 difference, $b b p^{n i g h t}-b b p^{d a y}$.

506

507 Field ADCP data: Global ADCP data were obtained from the Joint Archive for Shipboard

508 ADCP (JASADCP, http://ilikai.soest.hawaii.edu/sadcp/). We selected acoustic backscatter data

509 for the upper $20 \mathrm{~m}$ of the ocean surface (equivalent to the sampling depth of CALIOP) from

510 ADCPs with frequencies of 150 or $300 \mathrm{kHz}$ and excluded data from 38 and $75 \mathrm{kHz}$ frequencies.

511 The 150 and $300 \mathrm{kHz}$ frequencies better isolate scattering from the small $(\sim 0.5-5 \mathrm{~mm})$ animals

512 that are most likely detected by CALIOP due to their much greater abundances. Backscatter

513 amplitude $(E)$ measurements were converted into acoustic intensity $\left(I_{d B}\right)$ following Gostiaux and

514 van Haren ${ }^{40}$ :

515

$$
I_{d B}=10 \log \left(10^{k_{c} E / 10}-10^{k_{c} E_{n o i s e} / 10}\right),
$$

516 where $k_{c}$ is a scaling factor used to convert backscatter amplitude counts to decibels (dB), and

$517 E_{\text {noise }}$ is the noise floor of the individual ADCP dataset. Values of $k_{c}$ are frequency dependent

518 and were taken from Gostiaux and van $\operatorname{Haren}^{40}$. The noise floor was defined as the minimum

$519 k_{c} E$ for each individual data file. A total of 7,622 individual paired diel cycles were extracted

520 from the global database [Extended Data Fig. 4]. The geographic distribution of these diel cycle

521 data is largely biased to the regions surrounding the Hawaiian Islands, along the Tropical Ocean 
522 Atmosphere (TAO/TRITON) mooring array in the equatorial Pacific, the Southern California

523 Bight, between Chile and Antarctica, and off the northeast United States seaboard [Extended

524 Data Fig. 4]. Detailed inspection of echograms computed from each individual data file revealed

525 occasional time synchronicity issues, with the apparent deep DVM occurring more than 2 hour

526 before or after local sunrise/sunset. To validate the time stamp of each data file, we compared

527 the timing of the mesopelagic (max depth of the data file to $150 \mathrm{~m}$ ) DVM to the time of local

528 sunrise and sunset. Time synchronicity issues were detected in less than $10 \%$ of the data files.

529 The time stamp of these errant ADCP backscattering observations were corrected to synchronize

530 the deep DVM with sunrise/sunset prior to computing the day/night differences analyzed in the

531 manuscript.

532

533 Field time-series zooplankton biomass data: Monthly climatological migratory zooplankton

534 dry weight data shown in figure $3 \mathrm{c}$ for HOT were calculated from data in figure 1 of Hannides et

$535 \mathrm{al}^{21}$. Monthly climatological migratory zooplankton dry weight data shown in figure $3 \mathrm{~d}$ for

536 BATS were calculated from 1994 to 2017 data provided by D.K.S. The 1994 to 2011 subset of

537 these data were published as figure 2c in Steinberg et al. ${ }^{22}$.

539 Global phytoplankton net primary production, biomass, and division rate data:

540 Phytoplankton net primary production $(N P P)$ values used for figure $4 \mathrm{~b}, \mathrm{c}$, phytoplankton division

541 rates $(\mu)$ used for calculating $c_{1}$ in equation 6 , and phytoplankton biomass $\left(C_{p h y t o}\right)$ shown in

542 Extended Data Figure 6 are from the Carbon-based Production Model $(C b P M)^{41}$ using MODIS

543 passive ocean color data collected between 2008 and 2017 (data are available at

544 http://www.science.oregonstate.edu/ocean.productivity/). 
545 Author Information: Reprints and permissions information is available at

546 www.nature.com/reprints. The authors declare no competing financial interests. Correspondence 547 and requests for materials should be addressed to MJB.

548

549

550

551

552

553

554

555

556

557

558

559

560

561

562

563

564

565

566

567

568

Data Availability: The CALIOP lidar and field ADCP datasets analyzed during the current study are available at http://www.science.oregonstate.edu/ocean.productivity/ and from the Joint Archive for Shipboard ADCP at http://ilikai.soest.hawaii.edu/sadcp/. Data presented in figures 3b-d and $4 \mathrm{~b}$ and Extended Data figures 3, 6, 7, and 8 were provided as spate tabs in an excel file as part of this manuscript submission.

31. Winker, D. M., et al. Overview of the CALIPSO Mission and CALIOP Data Processing Algorithms. J. Atmos. Ocean Tech. 26, 2310-2323 (2009).

32. Behrenfeld, M.J. et al. The North Atlantic Aerosol and Marine Ecosystem Study (NAAMES): Science motive and mission overview. Frontiers Mar. Sci. 6, 122. doi: 10.3389/fmars.2019.00122 (2019).

33. Lu, X., et al. Retrieval of ocean subsurface particulate backscattering coefficient from spaceborne CALIOP lidar measurements. Opt. Express, 24, 29001-29008 (2016).

34. DuRand, M.D. \& Olson, R.J. Diel patterns in optical properties of the chlorophyte Nannochloris sp.: Relating individual-cell to bulk measurements. Limnol. Oceanogr., 43, 1107-1118 (1998). 
569 35. Vaulot, D., Marie, D., Olson, R. J., \& Chisholm, S.W. Growth of Prochlorococcus, a

570 photosynthetic prokaryote in the equatorial Pacific ocean. Science 268, 1480-1482 (1995).

571

572 36. André J.M., Navarette, C., Blanchot, J., \& Radenac, M.H. Picophytoplankton dynamics in 573 the equatorial Pacific: growth and grazing rates from cytometric counts. J. Geophys. Res.

$574 \quad 104,3369-80(1999)$.

575

576 37. Vaulot, D. \& Marie, D. Diel variability of photosynthetic picoplankton in the equatorial

577 Pacific. J. Geophys. Res. - Ocean 104, 3297-3310 (1999).

578

579

580

38. Binder, B.J. \& DuRand, M.D. Diel cycles in surface waters of the equatorial Pacific. DeepSea Res. II 49, 2601-2617 (2002).

581

582

39. Jacquet, S., Prieur, L., Avois-Jacquet, C., Lennon, J. F., \& Vaulot, D. Short-timescale

584 variability of picophytoplankton abundance and cellular parameters in surface waters of the Alboran Sea (western Mediterranean). J. Plankt. Res. 24, 635-651 (2002).

585

586

40. Gostiaux, L. \& Van Haren, H. Extracting meaningful information from uncalibrated backscattered echo intensity data. J. Atmo. Ocean. Techn. 27.5, 943-949 (2010).

588

41. Westberry, T.K., Behrenfeld, M.J., Siegel, D.A., \& Boss, E. Carbon-based primary productivity modeling with vertically resolved photoacclimation. Global Biogeochem. Cycles 22, GB2024, doi:10.1029/2007GB003078 (2008). 


\section{Extended Data Figure Legends}

593 Extended Data Figure 1: Global CALIOP observational coverage. (a-e) CALIOP ground

594 tracks for (a) one, (b) two, (c) four, (d) eight, and (e) sixteen days. (f) Number of months for each

$595 \quad 2^{\circ}$ latitude $\times 2^{\circ}$ longitude bin with day and night retrievals of $b b p$ for the 2008 and 2017 study

596 period. Total number of months possible is 115 . The north-south strip of low retrieval success

597 in the middle of the Pacific is caused by a gap in ancillary AMSER surface wind data, which is

598 used for flagging data with potential bubble contamination [Methods].

599

600

Extended Data Figure 2: Global distributions of monthly climatological average values of

601

$\Delta \boldsymbol{b b p}$. Thin black line $=$ contour of monthly average sea surface temperature of $15^{\circ} \mathrm{C}$. Heavy

602 black lines $=$ Monthly extent of the five subtropical gyres where annual average surface

603 chlorophyll concentrations are $\leq 0.08 \mathrm{mg} \mathrm{m}^{-3}$.

604

605

Extended Data Figure 3: Time series of $\Delta \boldsymbol{b} b \boldsymbol{p}$ for the PSO. (a-h) 2008 to 2017 monthly

606

values of $\Delta b b p(\%)$ for the eight PSO regions (labeled at top of each panel) identified in figure $3 \mathrm{a}$

607 of the main manuscript.

608

609 Extended Data Figure 4: Global coverage of field ADCP data. Number of days within each

$6105^{\circ}$ latitude by $5^{\circ}$ longitude bin that paired day-night ADCP data are available from the 1985 to

6112017 JASADCP-based field archive (http://ilikai.soest.hawaii.edu/sadcp/). Total number of days

612 possible is 11,680 . White bins $=$ no data. Yellow/black line $=$ contour of annual average sea

613 surface temperature of $15^{\circ} \mathrm{C}$. Heavy white lines $=$ boundaries of the eight PSO regions identified

614 in figure 3a of the main manuscript. 
Extended Data Figure 5: Influence of phytoplankton division rate and of day length on calculated DVM backscatter for the PSO. (a) Values for $c_{1}$ (see equation 6 in Methods of main manuscript) over the range of phytoplankton division rates $(\mu)$ in the PSO $(n=999$ monthly $\mu$ values for all PSO regions). Solid circle $=$ mean value of $\mu$ and $c_{l}$ for the PSO. Box

$620= \pm 1$ standard deviation from the mean value of $\mu$. (b) Values for $c_{2}$ (see equation 7 in Methods 621 of main manuscript) over the range of day lengths in the PSO ( $n=999$ monthly day length 622 values for all PSO regions). Solid circle $=$ mean day length and $c_{2}$ value for the PSO. Box $={ }_{ \pm} 1$ 623 standard deviation from the mean day length.

Extended Data Figure 6: Seasonal cycles in monthly mean regionally-integrated values of 626 DVM $M_{\text {CALIOP }}\left(\mathrm{g} \mathrm{m}^{-2}\right)$ and phytoplankton biomass $\left(C_{\text {phyto }} ; \mathrm{mg} \mathrm{C}^{-3}\right)$ for high-latitude regions. (a) North Pacific. (b) North Atlantic. (c) Southern Ocean. These three regions are identified in figure $4 \mathrm{c}$ of the main manuscript. Vertical lines $= \pm 1$ standard deviation $(\mathrm{n}=111$ monthly DVMCALIOP and $C_{\text {phyto }}$ values for each region). $C_{\text {phyto }}$ data are from the Carbon-based Production 630 Model $(C b P M)$ and MODIS passive ocean color data [Methods].

\section{Extended Data Figure 7: Comparison of CALIOP night-day $b b p$ differences and field} ADCP night-day differences in acoustic backscatter. Dashed line $=$ two-sided least squares

634 linear regression fit to data for the SPSG, NPSG, TP, STA, NASG, and NTA $(n=6)$. For 635 completeness, the average value for PSO bins outside our eight primary regions is indicated by 636 the white symbol. Symbols = regional average values with standard error bars (n for each region $637=19$ for SISG, 18 for SASG, 115 for TP, 16 for NASG, 23 for NTA, 59 for NPSG, 22 for STA, 
654

655

656

657 658 659

59 for SPSG, 302 for Other). Symbol colors identify region (labeled on right) and correspond to coloring in figure 3a of the main manuscript. Numbers next to each symbol indicate the median number of days with ADCP data within the 32-year field record for the $5^{\circ}$ latitude $\mathrm{x} 5^{\circ}$ longitude bins.

\section{Extended Data Figure 8: Bin-to-bin comparison of CALIOP $\triangle b b p$ and field-based DVM}

measurements in the PSO. (a) CALIOP normalized difference ratios $(\Delta b b p)$ versus field $\operatorname{ADCP}\left(\triangle B_{A D C P}\right)$ normalized difference ratios for $5^{\circ}$ latitude $\mathrm{x} 5^{\circ}$ longitude bins within the PSO. Black line $=$ two-sided least squares linear regression fit. Black line $=$ two-sided linear least squares regression relationship ( $\mathrm{F}$ test $\mathrm{p}$ value for slope $<0.001, \mathrm{n}=331$ independent geographical bins) for all data from our eight primary PSO regions (colored symbols, labeled on right). White symbols $=\mathrm{PSO}$ values for $5^{\circ} \times 5^{\circ}$ bins outside of the eight primary regions. Inclusion of these data in the linear regression analysis increases to the $\mathrm{F}$ test p-value to 0.005 ( $\mathrm{n}$ $=633$ independent geographical bins). (b) Relationship between field DVM biomass at the HOT site measured for a given calendar month and year (x-axis) versus DVM biomass measured during all other years for the same calendar month (y-axis).

55 Extended Data Figure 9: Field-based diel cycles in $\boldsymbol{b} \boldsymbol{b p}$. Average diel cycles in $b b p$ from Kheireddine and Antoine ${ }^{19}$ for (blue line) mixing $(\mathrm{n}=69$ days of measurements), (green line)

57 oligotrophy $(\mathrm{n}=322$ days of measurements), and (red line) declining $(\mathrm{n}=32$ days of measurements) conditions and (black line) the average of these three cycles, which corresponds to the diel cycle in Fig. 1b of the main manuscript. 
Figure 1

a
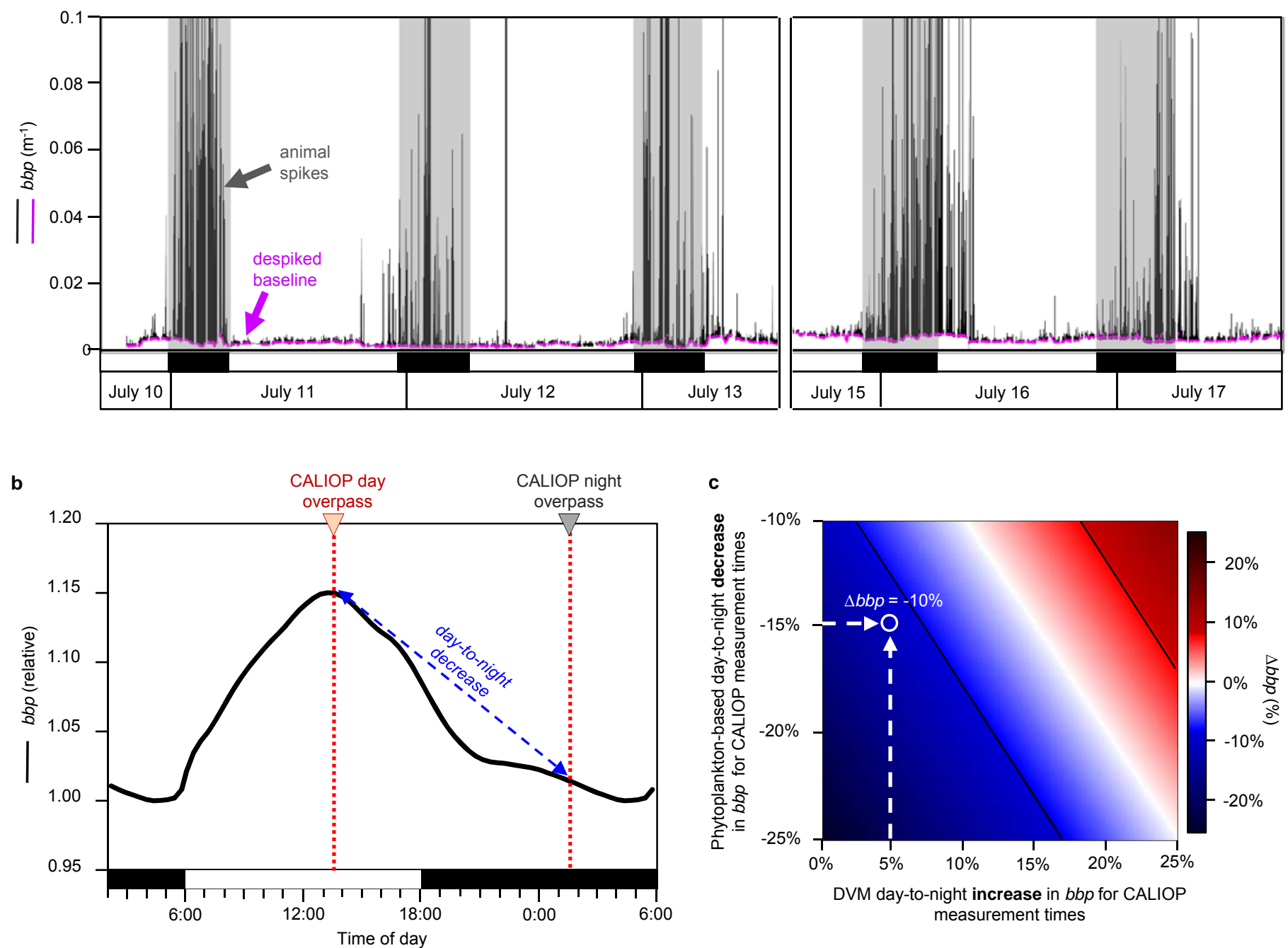
Figure 2

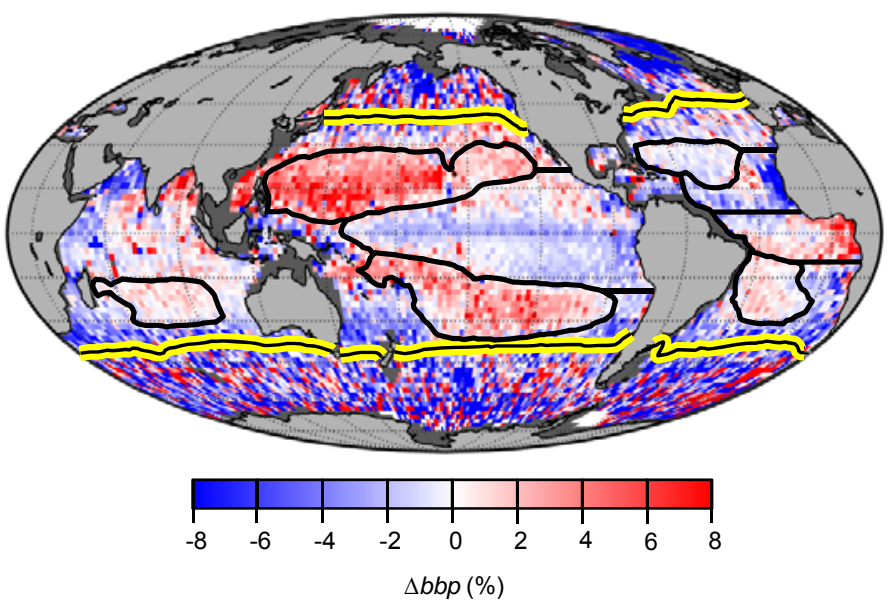


Figure 3

C

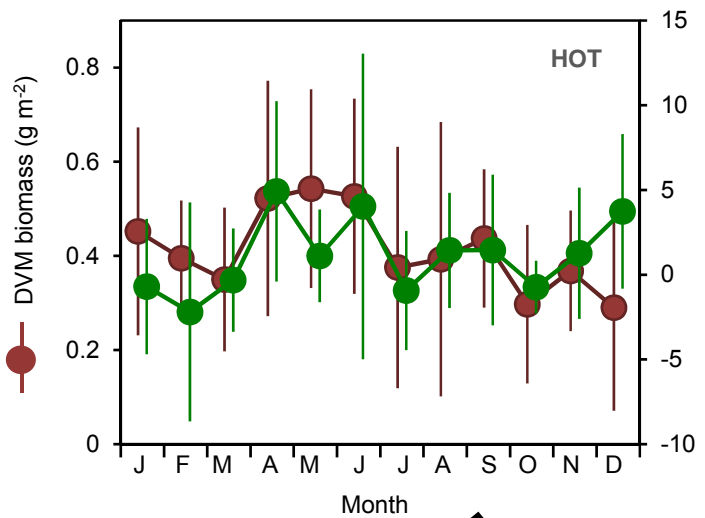

d

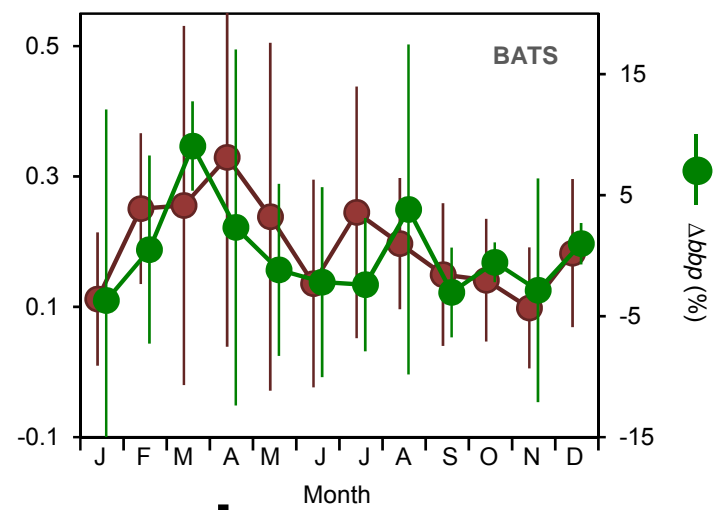

a

b

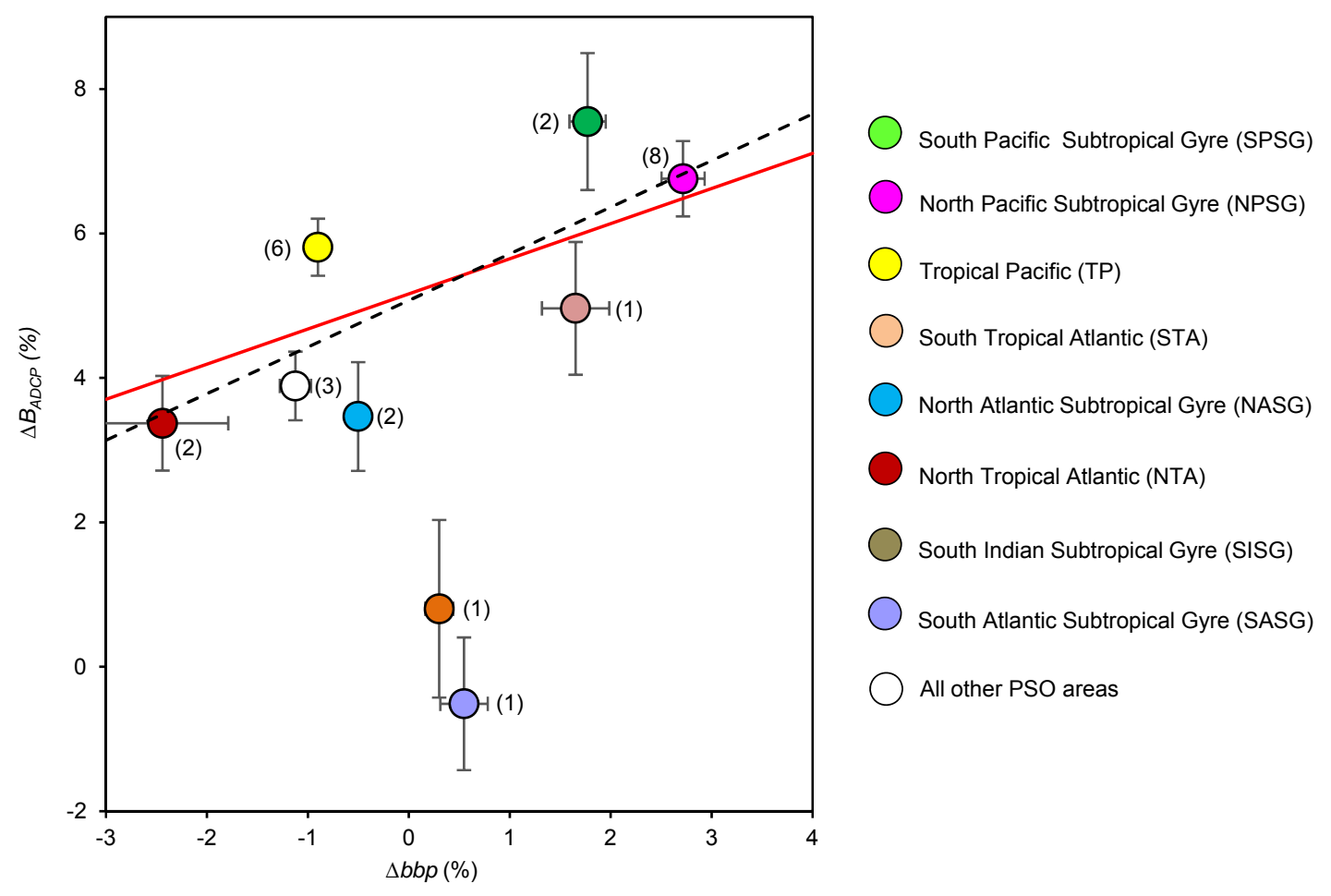


Figure 4

a

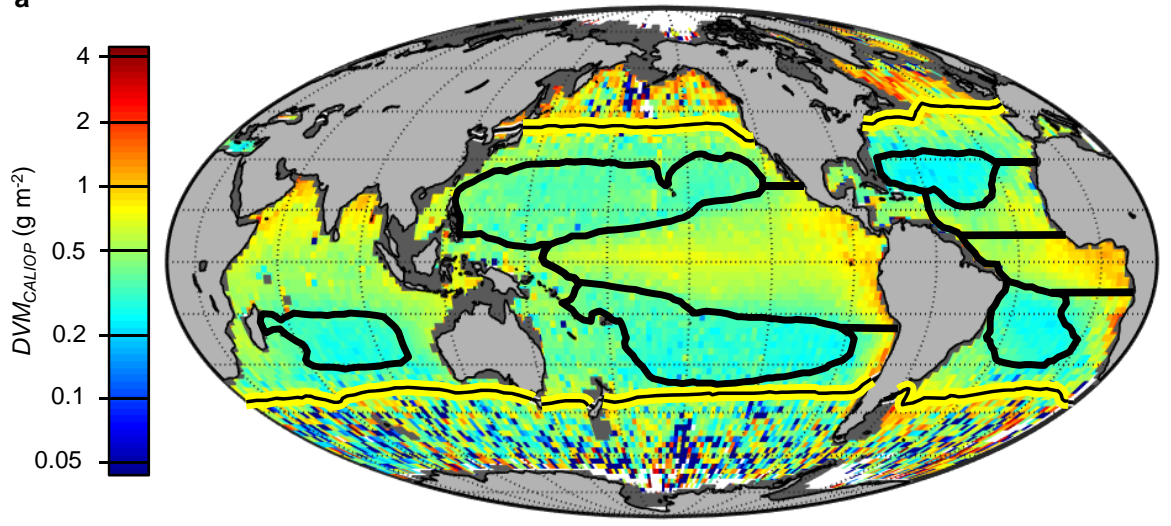

b

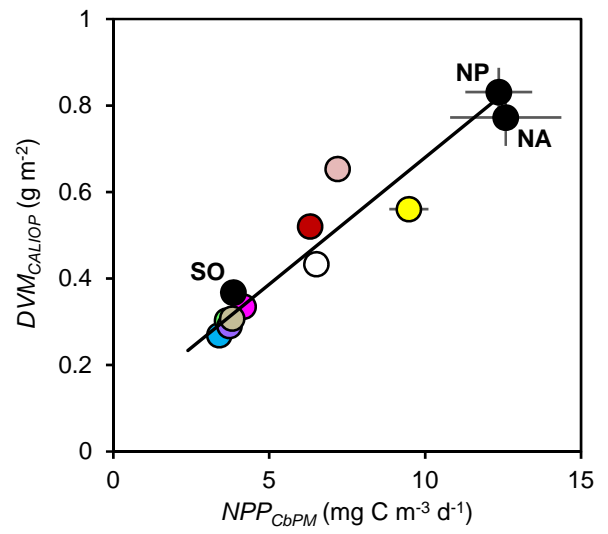

C

$\square \begin{aligned} & =D V M_{C A L I O P} \text { significantly } \\ & (p<0.05) \text { and positively }\end{aligned}$ correlated with NPP

$=D V M_{\text {CALIOP }}$ significantly $(p<0.05)$ and negatively correlated with $N P P_{C D P M}$

no outline $=D V M_{\text {CALIOP }}$ and $N P P_{C D P M}$ not significantly $(p>0.05)$ correlated
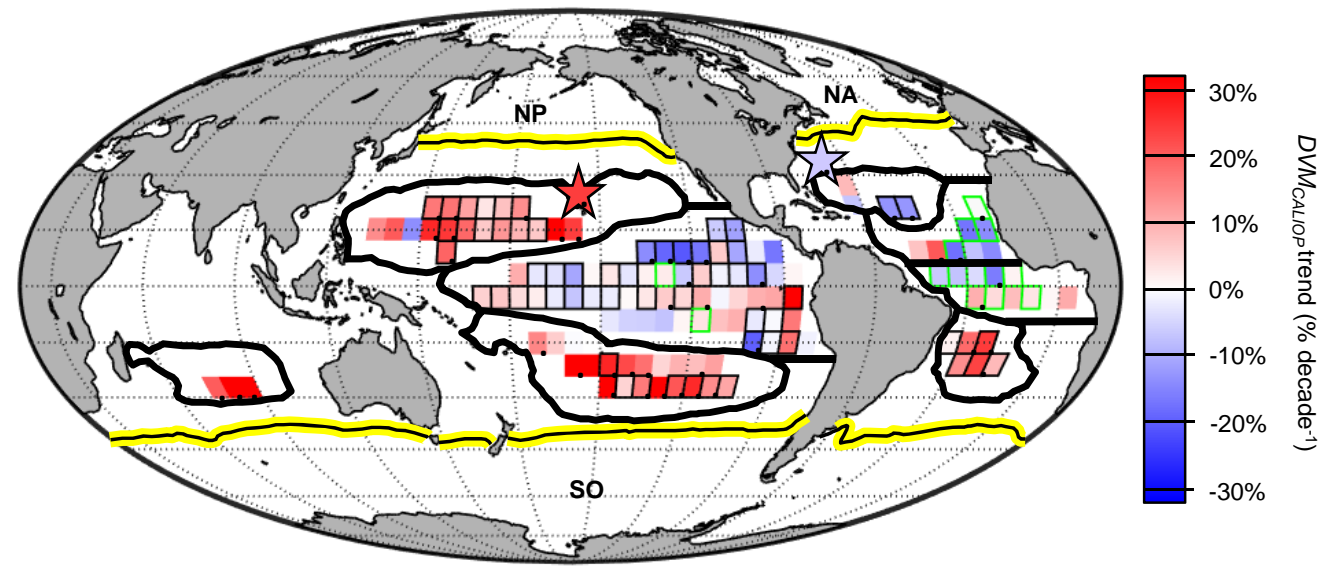


\section{Supplementary Discussion}

This file includes supplemental text for the manuscript, "Satellite-observed daily vertical migrations of global ocean animals", by Behrenfeld et al. regarding (1) CALIOP orbits and data binning, (2) high-latitude spatial variability in CALIOP retrievals, (3) normalized difference ratio data and results in figure 3 of the main manuscript, (4) calculation of the phytoplankton diel $b b p$ cycle, (5) additional details on calculations of DVM biomass, and (6) directions for future research.

1) CALIOP orbits and data binning: While satellite lidar measurements have become a common tool for atmospheric research, they are relatively new for studying ocean ecosystems ${ }^{11,14,15}$. Unlike familiar passive ocean color instruments that use a rotating telescope or 'push-broom' approach to achieve broad-swath measurements, the CALIOP instrument conducts its measurements at a near-nadir angle and only along its orbit tracks, which are oriented along the ground in opposite directions on the daylight and dark sides of the Earth. Extended Data Figure 1a shows day and night orbits for a single 24 hour period, illustrating how rare orbit cross-over points are for collecting spatially coincident data within a single day (and ocean retrievals for many of these will be prevented by clouds). Furthermore, even when ocean retrievals are successful at both times for a given cross-over point, the water sampled during the day will be different than that measured 12 hours later at night because surface waters are continuously moved by ocean currents. Because of these considerations, we used binned CALIOP data to evaluate global patterns in DVM animals rather than focusing only on spatially coincident data. Binning was also necessary for comparing CALIOP results to field data (which are also spatially and temporally sparse). 
While not providing broad swaths of data like an ocean color sensor, advantages of CALIOP are that it provides measurements during the day and night and its rapid laser pulse rate enables measurements every $330 \mathrm{~m}$ along the ground. In addition, its precessing orbit allows for fullyglobal sampling over its 16-day repeat cycle. Extended Data Figures 1a-e illustrate how this global coverage builds-up over 1, 2, 4, 8, and 16 days. Thus, for a given spatial binning resolution, the CALIOP approach can provide a dense within-bin 'sampling' over the course of a month. Averaging these repeated measurements within a monthly bin reduces noise in the retrieved ocean property and allows the signal of interest to be isolated. As discussed in Section 2 below, the number of successful day and night retrievals within a bin depends on atmospheric conditions (cloud cover, aerosol thickness), which vary strongly with latitude.

In our first publication using CALIOP data ${ }^{14}$, we validated satellite-retrieved $b b p$ values using coincident ship-based and airborne-based field measurements. We then binned global CALIOP data into $2^{\circ}$ latitude $\times 2^{\circ}$ longitude bins to evaluated global patterns in phytoplankton biomass and total particulate carbon concentration. The same $2^{\circ} \times 2^{\circ}$ binning was used in the current manuscript for figure 2. In our second CALIOP publication ${ }^{15}$, we demonstrated an excellent agreement between CALIOP and ocean color based seasonal cycles in $b b p$ and then used $1^{\circ} \times 1^{\circ}$ binned data to evaluate phytoplankton bloom dynamics. This slightly higher spatial resolution was used because the study was geographically restricted to the north and south polar regions, whereas $2^{\circ} \times 2^{\circ}$ binning is appropriate for the global scope of the current study. For figure 3b of the current manuscript, a coarser resolution of $5^{0} \times 5^{0}$ was used because of the very sparce coverage of ADCP data. Finally, $6^{\circ} \times 6^{\circ}$ binning was used for figure 4c because (1) smaller bins 
make it difficult to distinguish the outlines and dots used for each bin that indicate statistical significance and (2) the enhanced signal-to-noise of the larger bins improves detection of temporal trends (i.e., de-seasoned anomalies) in DVMCALIOP.

2) High-latitude zones: At latitudes poleward of the PSO, CALIOP retrievals of the DVM signal remain noisy between the spatial bins used for our analysis. In contrast, these retrievals exhibit significantly better spatial coherence within the PSO. Consequently, we have largely restricted our more detailed analyses of the CALIOP record to these lower-latitude PSO regions. A number of factors contribute to the noisy spatial maps of the DVM signal at high latitudes. First and foremost of these factors is the combined impact of spatial and temporal variability in plankton ecosystems, persistent cloudiness, and the sampling coverage of CALIOP. Extended Data Figure 1f shows the total number of months within the 2008 - 2017 period (115 total possible) for each $2^{\circ}$ latitude $\times 2^{\circ}$ longitude bin with at least one day and one night retrieval of $b b p$. This latter figure clearly shows the much poorer coverage at high latitudes, but even this stark difference between high latitudes and the PSO over-represents high-latitude coverage. CALIOP's small single-shot footprint (100 $\mathrm{m}$ at the ocean surface) allows successful retrievals between even small gaps in cloud cover. Thus, even if a given bin is largely overcast for an entire month (as is often the case at higher latitudes), a single day and night retrieval through gaps in the clouds would yield a day-night pair for that month and add to the total number of measurement pairs for that bin in Extended Data Figure 1f. These two points could come from different locations anywhere within the $2^{\circ} \times 2^{\circ}$ bin and may be separated in time by nearly a month. In such a case, spatial and temporal variations in the plankton community can be a large contributor to the calculated night-day difference. As cloudiness decreases from this extreme 
example, many more CALIOP retrievals can be averaged together within a given $2^{\circ} \times 2^{\circ}$ bin, thereby dampening the influence of plankton community spatial and temporal variations and better isolating the DVM signal (as discussed above). In the PSO, clear sky scenes are far more common than at higher latitudes. With a $100 \mathrm{~m}$ single-pulse footprint and a $330 \mathrm{~m}$ ground distance separation between pulses, $>600$ measurements can be collected within a given $2^{\circ} \times 2^{\circ}$ bin on a single day or night overpass under clear skies. With clear sky conditions for even two overpasses per month, this means that $>1200$ daytime measurements and $>1200$ nighttime measurements spanning the breadth of the bin may be available to calculate a single monthly average night-day difference. In addition, temporal variability in plankton stocks within the $2^{\circ} \mathrm{x}$ $2^{\circ}$ bins of the PSO tend to be smaller than most high-latitude bins. Thus within the PSO, effective retrieval of the DVM signal at $2^{\circ} \times 2^{\circ}$ binning resolution is far more likely than at higher latitudes. One solution to the 'spatial speckling' problem at high latitudes is to average data over a much larger area. When we do this, we find that regionally-integrated annual average $D V M_{C A L I O P}$ for the three high-latitude regions shows a relationship with annual average mixed layer net primary production that is highly consistent with that found for the PSO regions [Fig. 4b]. Furthermore, regionally-integrated monthly DVMCALIOP data for the three high-latitude regions exhibit strong annual cycles consistent with both the magnitude and seasonality of phytoplankton biomass in these regions [Extended Data Fig. 6].

In addition to the above considerations regarding high latitude retrievals, phytoplankton community composition in these regions tends to be more diverse than in the PSO, division rates vary strongly with season and are poorly constrained by satellite productivity algorithms, and it is highly likely that cell division cycles are often not synchronized to the daily light-dark cycle. 
The impact of these ecological considerations on the phytoplankton night-day difference is currently unresolved (see Section 6 below).

3) Normalized difference ratios: In figure 2 of the main manuscript, we compare CALIOP retrievals of $\Delta b b p$ with normalized difference ratios calculated from field ADCP measurements. We used normalized difference ratios (equations 1 and 2 in the main manuscript) for this comparison for two primary reasons. First, division of night-day differences by daytime values makes the retrieved property biomass-specific, allowing an evaluation of the relative contribution of DVM animals. Second, normalization to daytime values, at least in part, helps reduce the influence of instrument-dependent variations in the field measurements. Specifically, the ADCP acoustic backscatter record used in the current study was compiled from more than 30 research vessels and 2,000 field surveys. Differences between the instruments used, how they are mounted, and how they are calibrated can generate instrument-dependent differences in the resultant backscattering data that are not linked to real differences in in situ particle backscattering. By calculating the normalized difference ratio, the influence of this instrumentdependent contribution is reduced. To illustrate the significance of this normalization, the ADCP-CALIOP comparison presented in figure $3 \mathrm{~b}$ of the main manuscript was revised by substituting the normalized difference ratios with simple differences (i.e., y-axis $=I_{d B^{n i g h t}}-I_{d B}{ }^{d a y}$; $\mathrm{x}$-axis $=b b p^{\text {night }}-b b p^{d a y}$ ) for each data set [Extended Data Fig. 7]. The outcome of this analysis is similar to the result presented in figure 3b of the main manuscript. Specifically, (1) the relative location of each regional average value is the same between graphs and (2) results for the SISG and SASG regions deviate from the other regions in the same manner in both graphs. The primary difference (as expected from the above discussion) is that the linear regression on the 
regional ADCP and CALIOP values shown in figure 3b gives an $\mathrm{r}^{2}=0.55$ and $\mathrm{p}=0.09$, whereas the same comparison for data in Extended Data Fig. 7 gives an $\mathrm{r}^{2}=0.39$ and $\mathrm{p}>0.10$.

In figures $3 c$ and $3 \mathrm{~d}$, we also compare $\Delta b b p$ to DVM biomass measured at the HOT and BATS sites. The expectation is that, across the PSO, DVM biomass will be more quantitatively related to the simple difference, $b b p^{D V M}=b b p^{n i g h t}-c b b p^{d a y}$, than the normalized difference ratio. Since $b b p^{D V M}$ and $\Delta b b p$ have nearly the exact same seasonal cycle at HOT and BATS $\left(\mathrm{r}^{2}=0.99, \mathrm{p}<\right.$ 0.001), we chose to show the CALIOP normalized difference ratio data in figures $3 c$ and $3 d$ simply to be consistent with figure 3b. However, as described in the main manuscript, the actual calculation of DVM biomass is based on the simple difference, $b b p^{D V M}$.

As discussed in the main text and in the Methods section, creating an adequate field data set (with respect to PSO coverage) for comparison with CALIOP data required aggregating historical ADCP data from over 30 years (1985 to 2017). Even over this long period, most of our $5^{\circ} \times 5^{\circ}$ bins have only one to a few days of data, and many of these observation pre-date CALIOP. Due to this paucity of data and their temporal mismatches with CALIOP, figure $3 \mathrm{~b}$ in the main manuscript focuses on the correspondence between regional values of $\triangle B_{A D C P}$ and $\triangle b b p$. However, we also report that linear regression analysis of $\triangle B_{A D C P}$ and $\triangle b b p$ data for all $5^{\circ}$ $x 5^{\circ}$ bins within the eight primary PSO regions yielded a highly significant slope similar to the relationship calculated from the regionally binned data. Extended Data Fig. 8a shows this relationship, where data are color-coded following the regional coloring scheme shown in figure 3a of the main manuscript. As expected, the relationship for all individual data exhibits significant scatter around the least squares linear regression line $\left(r^{2}=0.04\right)$. We can use the 
HOT time series field measurement of DVM biomass to put this result in context. Specifically, we can ask how much predictive skill does knowledge of DVM biomass during a given month of a given year provide in estimating DVM biomass for the same month but other years in the HOT record. This result is shown in Extended Data Fig. 8b. The implication here is that there is a large amount of year-to-year variability in monthly DVM biomass within field records and thus considerable scatter is expected between CALIOP and field ADCP data when compared at the level of individual measurements [Extended Data Fig. 8a], particularly when the two data sets are collected during different years. However, when data are averaged over time and space, clear regional differences emerge in DVM strength and these patterns are consistent between the ADCP and CALIOP records for all PSO regions except the SASG and SISG [Fig. 3b] (see Section 6 below). A corollary to this result is found in the published studies of Hannides et al. ${ }^{21}$ and Steinberg et al..$^{22}$, where an annual cycle in DVM biomass becomes clear by calculating monthly average values for field records extending a decade or more. Because of the large variability between years in the monthly data [e.g., Extended Data Fig. 8b], these cycles are difficult to decipher in the full time-series records.

4) Phytoplankton diel bbp cycle: Historical studies on diel cycles in ocean inherent optical properties have largely focused on the particulate beam attenuation coefficient ${ }^{42-44}$. To our knowledge, the only published account of diel cycles in $b b p$ are from Kheireddine and Antoine ${ }^{19}$. In their study, five years of $b b p$ data were evaluated from the long-term, deep-water (2440 m) BOUSSOLE buoy site in the Mediterranean Sea. Over this period, 1322 total days of data were collected, from which the authors selected 737 days of highest data quality. These data were then separated into mixing, declining, oligotrophic, and bloom-climax phases with respect to 
phytoplankton biomass. A vast majority of the data were from the three former phases, which are most representative of the PSO. The average diel cycle in $b b p$ for each of these phases is reproduced as the blue, red, and green lines, respectively, in Extended Data Fig. 9. The average of these three diel cycles is shown as the black line in Extended Data Fig. 9 and this averaged cycle corresponds to the diel cycle shown in figure 1b of our main manuscript. The bloomclimax data in (19) exhibits a similar diel cycle as during the other seasons but with a daytime peak 2 hour later in the afternoon.

5) DVM biomass calculations: The biomass of DVM animals (DVMCALIOP) was calculated from CALIOP-measured night $\left(b b p^{n i g h t}\right)$ and day $\left(b b p^{d a y}\right)$ differences in $b b p$ following [Eq. 3 of main manuscript]:

$$
D V M_{C A L I O P}=a\left(b b p^{n i g h t}-c_{1} c_{2} b b p^{d a y}\right),
$$

where $c_{1}$ accounts for growth rate $\left(\mu\right.$; divisions day $\left.{ }^{-1}\right)$ dependent night-day differences in $b b p$ due to the phytoplankton diel cycle [Fig. 1b], $c 2$ accounts changes in night-day $b b p$ differences caused by variations in day length, and $a$ is an empirical conversion factor between the backscatter signal of DVM animals ( $b b p^{D V M}$ ) and zooplankton biomass. In the following three subsections, we provide details on the derivation of $c_{1}, c_{2}$, and $a$.

For the current study, we did not attempt to introduce an additional correction factor to account for community composition effects on the phytoplankton diel $b b p$ cycle because (1) community composition is relatively conserved in the open ocean regions of the PSO (at least compared to higher latitude and coastal regions), (2) very little is known from targeted field or laboratory studies about taxonomic influences on the diel $b b p$ cycle, and (3) satellite-based global 
determinations of phytoplankton community composition are still relatively immature and would likely add more errors than improvements in our estimates of DVMCALIOP. Beyond taxonomic considerations, we also evaluate whether regional time series in $b b p^{\text {night }}$ - $b b p^{d a y}$ covaried with other globally-retrieved ocean properties (surface chlorophyll $a$ concentration, euphotic zone depth, median mixed layer light level, surface PAR, mixed layer depth, sea surface temperature), but found no unique relationships consistent across regions that could not be attributed to corollary relationships between these other ocean properties and variations in phytoplankton growth rates.

Dependence on division rate: Very few controlled studies have been conducted that enable a quantitative assessment of growth rate dependent variability in the phytoplankton diel $b b p$ cycle. One notable exception is the study of DuRand and Olson ${ }^{34}$. In that study, diel cycles in scattering cross section were reported for cultures of Nannochloris (chosen as representative of the small phytoplankton found in oligotrophic waters) grown under daily light-dark irradiance cycles of intensity ranging from 60 to $1500 \mu$ mole photons $\mathrm{m}^{-2} \mathrm{~s}^{-1}$. Cell division cycles in all cultures were tightly phased with the light:dark cycle, with division occurring in the dark (as is the case in the PSO). The relationship between growth irradiance and $\mu$ (divisions day $^{-1}$ ) was extracted from figure 3 of DuRand and Olson $^{34}$. Daytime maxima and nighttime minima in scattering cross section were extracted for each growth condition from figure 6 of DuRand and Olson $^{34}$. The relationship between these minimum and maximum values and values that would be observed during the CALIOP measurement times was calculated using the field-based diel cycle in figure $1 \mathrm{~b}$ of the current manuscript (see Section 4 above). A two-sided least squares linear regression analysis was then conducted on the relationship between the night-day 
difference in these scattering values and $\mu\left(\mathrm{r}^{2}=0.40, \mathrm{p}=0.12, \mathrm{n}=6\right)$. However, this relationship does not provide a description of $c_{l}$ because it is based on a pure phytoplankton culture, whereas $b b p$ data from CALIOP includes additional ‘background' scattering from other nonphytoplankton components. This issue was addressed by considering the results presented in figure $1 \mathrm{~b}$ where the field-measured diel cycle in $b b p$ gives a day-to-night decrease in $b b p$ of $\sim 15 \%$. These field data were collected in the Mediterranean Sea where the dominant prokaryotic and picoeukaryotic phytoplankton divide at a rate slightly less than 1 division day ${ }^{-1}$. Thus, assuming a bulk phytoplankton division rate of $\sim 0.8$ division day ${ }^{-1}$, a 'background' $b b p$ signal was added to our DuRand and Olson ${ }^{34}$ based two-sided linear regression result until a value for $c_{l}$ of 0.85 was achieved for $\mu=0.8$ division day $^{-1}$. This resultant description for $c_{l}$ is:

$$
c_{1}=0.929-0.122 \mu .
$$

The mean, standard deviation, and range for $c_{l}$ values in the PSO are shown in Extended Data Fig. 5a.

Dependence on day length: The dependence of $c$ on day length exists because a change in day length causes the two CALIOP sampling points (determined by its fixed orbit) to line up differently with the phytoplankton diel cycle. To account for this effect, the field-based diel cycle in $b b p$ shown in figure $1 \mathrm{~b}$ was split into its daytime and nighttime components. The duration of these day and night components was then expanded and contracted to create diel cycles for day lengths ranging from 4 to 20 hours (i.e., outside this range both CALIOP measurement times either occur in the day or the night). The night-day difference in $b b p$ was then calculated for the two CALIOP measurement times for each day length. For the highly constrained range in day length across the PSO $(10-14 \mathrm{~h})$, the relationship between these night- 
day difference values and day length is linear $\left(r^{2}=1.0, p<0.001\right)$. This relationship was then adjusted to give a value of 1 for a 12:12 day:night cycle (i.e., the day length corresponding to the data in figure 1b). The resultant relationship is:

$$
c_{2}=0.986+0.0012 d l \text {, }
$$

where $d l=$ day length (h). The mean, standard deviation, and range for $c_{2}$ values in the PSO are shown in Extended Data Fig. 5b, with the full range being highly constrained to $c_{2}=0.998$ to 1.002. Thus, inclusion of $c_{2}$ in our calculation of DVM biomass is more for completeness than as an important correction in the calculation of DVMCALIOP.

Over a broader range of day lengths, the relationship between night-day difference values and day length becomes nonlinear and, when normalized to 1 for a 12:12 day:night cycle is described by $\left(\mathrm{r}^{2}=1.0, \mathrm{p}<0.001\right)$ :

$$
c_{2}=-7 \mathrm{E}-06 d l^{4}+0.0004 d l^{3}-0.0069 d l^{2}+0.06 d l+0.8013
$$

which for a day length range of 4 to 20 hours gives a slightly larger range of values for $c_{2}$ of 0.952 to 1.006 .

Scaling $b b p^{D V M}$ to $D V M_{C A L I O P}:$ Our primary motivation for scaling $b b p^{D V M}$ to $D V M_{C A L I O P}$ was to convert the former property with units of $\mathrm{m}^{-1}$ into a more ecologically-understandable property with units of $\mathrm{g} \mathrm{m}^{-2}$ dry weight. For this conversion, we use a constant scaling factor, meaning that the results shown in figure 4 of the main manuscript can be interchanged between the directly-measured CALIOP property, $b b p^{D V M}$, and the scaled biomass property, DVMCALIOP. Our approach for quantifying the scaling factor between $b b p^{D V M}$ to $D V M_{C A L I O P}$ was similar to that used for more standard satellite ocean color products, such as surface chlorophyll concentration. 
Specifically, we used field data collected coincidently (in this case at the monthly time scale) with CALIOP. For the current study, this means that we limited our analysis to BATS field data collected between 2008 and 2017, which yielded a conversion factor of 1596 g dry weight m ${ }^{-1}$. If we had instead combined these BATS data with monthly average DVM biomass data from HOT (1994 to 2005) adjusted for the apparent 23\% increase since the end of the field record (see main manuscript), then the resultant conversion factor would have been $1402 \mathrm{~g}$ dry weight $\mathrm{m}^{-1}$.

6) Future directions: The current manuscript describes the first attempt to connect a satelliteretrieved property $(b b p)$ to animal biomass and distributions in the global ocean. As is standard practice in satellite oceanography, we have used the best available in situ observations (ADCP and zooplankton biomass time-series data) to validate the CALIOP retrievals before attempting an interpretation of their ecological meaning. As should be expected with any such new satellite product, additional future studies and new technologies are needed to both evaluate and constrain uncertainties in our analysis and to expand upon the capabilities of CALIOP for studying global ocean DVM animals. The following list provides some examples.

i. Phytoplankton diel bbp cycle: CALIOP retrieved $\Delta b b p$ span from negative to positive values because nighttime increases in $b b p$ from DVM animals are countered by a background phytoplankton diel cycle that decreases $b b p$ from day to night. We have used data from the only published study that has quantified the phytoplankton diel $b b p$ cycle in the field ${ }^{19}$. These data were collected at a single location in the Mediterranean Sea and, while a range of phytoplankton populations were encountered during that study, similar analyses are needed in other ocean regions with different phytoplankton 
populations to evaluate the robustness of our description of phytoplankton diel $b b p$ changes. These analyses should include populations where cell division of the dominant species are synchronized over the diel cycle and also populations where cell division is not synchronized, as the latter case is likely common at higher latitudes.

It is important to recognize that the assessment of phytoplankton diel $b b p$ cycles in the field is not as straightforward as it might initially appear. The problem is that the cycle of interest is the biomass-normalized cycle, so an appropriate (preferably independent) assessment of biomass is needed, particularly when measurements are conducted on a moving ship. One potential approach is to divide $b b p$ by coincident measurements of chlorophyll concentration, but this approach will typically fail because cellular chlorophyll concentrations also have a diel cycle of their own that will result in an incorrect cycle for biomass-normalized $b b p$. In the study of Kheireddine and Antoine ${ }^{19}$, measurements were conducted from a fixed location (rather than a moving ship) and $b b p$ values measured over each diel cycle were normalized to the value measured at dawn. However, even for this study, physical advection of the surface layer ensures that different populations were sampled over each diel cycle, which may largely be the reason that this earlier study typically found that $b b p$ values at the end of a given diel cycle were not the same as at the beginning ${ }^{19}$. A great advantage of the Kheireddine and Antoine ${ }^{19}$ study was that investigators had a large number of daily cycles in $b b p$ to work with and thus, through averaging, they arrived at consistent cycles under various growth conditions (see Section 4 above). 
An alternative approach for addressing uncertainties in the phytoplankton diel $b b p$ cycle would be to conduct a series of laboratory experiments (much like that of DuRand and Olson $^{34}$ ) where different phytoplankton species are synchronized to light-dark cycles of various durations and changes in $b b p$ are continually monitored over the diel cycle. Such experiments should also encompass a range in growth rates for each species to enable development of predictive relationships.

ii. $\quad$ DVM biomass: In the current study, we convert CALIOP retrievals of $b b p^{D V M}$ into an estimate of DVM animal biomass using data from a single field time-series data set (i.e., BATS). This conversion was largely conducted to put CALIOP results in more intuitive ecological units (see Section 5 above), but there is significant uncertainty in this single conversion factor. Specifically, the backscattering efficiency of DVM animals depends on animal size, shape, composition, and other factors and the CALIOP-coincident BATS time-series data do not encompass every type of DVM animal found in the global oceans. Achieving more accurate estimates of $D V M_{C A L I O P}$ from $b b p^{D V M}$ will require a broader diversity of field samples, an increase in the number of time-resolved DVM animal properties characterized, and a detailed optical model linking these properties to backscattering.

iii. Spatial sampling: As discussed in detail above, spatial binning is required to achieve low-noise day-night match-up data with CALIOP. These binned data must then be validated with field observations that are typically collected at much smaller scales (e.g., the size of the opening of a zooplankton net or the footprint of a ship ADCP). A future 
study is needed to assess uncertainties in this spatial disconnect by providing a direct measurements that span the sampling scales of field zooplankton and CALIOP data. One potential approach here would be to couple ship-based DVM animal and backscattering measurements with airborne lidar measurements. In this scenerio, the airborne measurements could be conducted along a flight pattern that encompasses the retrieval scale of a satellite lidar, and might even be coordinated with simultaneous CALIOP overpasses (as in Behrenfeld et al. ${ }^{14}$ ), assuming CALIOP is still operational.

iv. South Indian and South Atlantic Subtropical Gyres: When regionally-averaged field ADCP and CALIOP data are compared [Fig. 3B, Extended Data Fig. 7], results for the SISG and SASG deviate from the other PSO regions. Potential reasons for this discrepancy are discussed in the main manuscript. Of particular concern is the low number of ADCP data available for these two regions in the historical record and their temporal disconnect with the CALIOP record. However, it is noteworthy that the individual bin data for the SISG and SASG actually span a considerable fraction of the range of variability in $\triangle b b p$ and $\triangle B_{A D C P}$ found for the other PSO regions [Extended Data Fig. 8a]. Clearly, additional field sampling campaigns are needed in the SISG and SASG to investigate the underlying basis of the apparent discrepancy in regionally-averaged $\triangle b b p$ and $\triangle B_{A D C P}$ values.

v. New technology: CALIOP was designed for atmospheric science, not ocean applications. It provides information on ocean $b b p$ for only a single $22 \mathrm{~m}$ depth bin immediately below the ocean's surface. High Spectral Resolution Lidar (HSRL) instruments have been 
developed since the launch of CALIOP and extensively field demonstrated from aircraft over a diversity of ocean regimes. These instruments can retrieve $b b p$ values deep within the sunlit surface layer of the ocean with meter-scale vertical resolution. If this technology is transferred to a satellite instrument, the HSRL approach could yield both improved accuracy in $b b p$ retrievals and an assessment of DVM animal nighttime vertical distributions. It is conceivable that vertically resolved DVM retrievals could provide information on feeding behavior linked to phytoplankton production layers and more accurate assessments of DVM biomass, as only those DVM animals that reach the upper $22 \mathrm{~m}$ of the surface are currently detected by CALIOP.

\section{References}

42. Siegel, D.A., Dickey, T.D., Washburn, L., Hamilton, M.K., \& Mitchell, B.G. Optical determination of particulate abundance and production variations in the oligotrophic ocean, Deep Sea Res. Part A 36, 211-222, doi:10.1016/0198-0149(89)90134-9 (1989).

43. Stramski, D., Shalapyonok, A., \& Reynolds, R. A. Optical characterization of the oceanic unicellular cyanobacterium Synechococcus grown under a day-night cycle in natural irradiance. J. Geophys. Res.-Ocean. 100, 13295-13307 (1995).

44. Dall'Olmo, G., et al. Inferring phytoplankton carbon and eco-physiological rates from diel cycles of spectral particulate beam-attenuation coefficient. Biogeosci. 8, 3423-3439 (2011). 


\section{Extended Data}

This file includes all Extended Data for the manuscript, "Global satellite observations of vertically migrating animals in the ocean's surface layer", by Behrenfeld et al. This file includes the following materials:

1) Extended Data Figure 1: Global CALIOP ground tracks for (a) one, (b) two, (c) four, (d) eight, and (e) sixteen days. (f) Number of months for each $2^{\circ}$ latitude $\times 2^{\circ}$ longitude bin with day and night retrievals of $b b p$ for the 2008 and 2017 study period. Total number of months possible is 115 . The north-south strip of low retrieval success in the middle of the Pacific is caused by a gap in ancillary AMSER surface wind data, which is used for flagging data with potential bubble contamination [Methods].

2) Extended Data Figure 2: Global distributions of monthly climatological average values of $\Delta b b p$. Thin black line $=$ contour of monthly average sea surface temperature of $15^{\circ} \mathrm{C}$. Heavy black lines $=$ Monthly extent of the five subtropical gyres where annual average surface chlorophyll concentrations are $\leq 0.08 \mathrm{mg} \mathrm{m}^{-3}$.

3) Extended Data Figure 3: 2008 to 2017 monthly values of $\Delta b b p(\%)$ for the eight PSO regions (labeled at top of each panel) identified in figure 3a of the main manuscript.

4) Extended Data Figure 4: Number of days within each $5^{\circ}$ latitude by $5^{\circ}$ longitude bin that paired day-night ADCP data are available from the 1985 to 2017 JASADCP-based field archive (http://ilikai.soest.hawaii.edu/sadcp/). Total number of days possible is 11,680. White bins $=$ no data. Yellow/black line $=$ contour of annual average sea surface temperature 
of $15^{\circ} \mathrm{C}$. Heavy white lines $=$ boundaries of the eight PSO regions identified in figure $3 \mathrm{a}$ of the main manuscript.

5) Extended Data Figure 5: (a) Values for $c_{l}$ (see equation 6 in Methods of main manuscript) over the range of phytoplankton division rates $(\mu)$ in the PSO. Solid circle $=$ mean value of $\mu$ and $c_{1}$ for the PSO. Box $= \pm 1$ standard deviation from the mean value of $\mu$. (b) Values for $c_{2}$ (see equation 7 in Methods of main manuscript) over the range of day lengths in the PSO. Solid circle $=$ mean day length and $c_{2}$ value for the PSO. Box $= \pm 1$ standard deviation from the mean day length.

6) Extended Data Figure 6: Monthly mean regionally-integrated values of $D V M_{C A L I O P}\left(\mathrm{~g} \mathrm{~m}^{-2}\right)$ and phytoplankton biomass $\left(C_{\text {phyto }} ; \mathrm{mg} \mathrm{C} \mathrm{m}^{-3}\right)$ for the high-latitude (a) North Pacific, (b) North Atlantic, and (c) Southern Ocean regions identified in figure $4 \mathrm{c}$ of the main manuscript. Vertical lines $= \pm 1$ standard deviation. $C_{\text {phyto }}$ data are from the Carbon-based Production Model (CbPM) and MODIS passive ocean color data [Methods].

7) Extended Data Figure 7: Comparison of CALIOP night-day $b b p$ differences and field ADCP night-day differences in acoustic backscatter. Dashed line $=$ two-sided least squares linear regression fit to data for the SPSG, NPSG, TP, STA, NASG, and NTA. For completeness, the average value for PSO bins outside our eight primary regions is indicated by the white symbol. Symbols = regional average values with standard error bars. Symbol colors identify region (labeled on right) and correspond to coloring in figure $3 \mathrm{a}$ of the main manuscript. Numbers next to each symbol indicate the median number of days with ADCP data within the 32 -year field record for the $5^{\circ}$ latitude x $5^{\circ}$ longitude bins. 
8) Extended Data Figure 8: (a) CALIOP normalized difference ratios ( $\Delta b b p$ ) versus field $\operatorname{ADCP}\left(\triangle B_{A D C P}\right)$ normalized difference ratios for $5^{\circ}$ latitude $\mathrm{x} 5^{\circ}$ longitude bins within the PSO. Black line $=$ two-sided least squares linear regression fit. Black line $=$ linear least squares regression relationship $(\mathrm{p}$-value for slope $<0.001, \mathrm{n}=331$ ) for all data from our eight primary PSO regions (colored symbols, labeled on right). White symbols $=$ PSO values for $5^{\circ} \times 5^{\circ}$ bins outside of the eight primary regions. Inclusion of these data in the linear regression analysis increases to the p-value to $0.005(\mathrm{n}=633)$. (b) Relationship between field DVM biomass at the HOT site measured for a given calendar month and year (x-axis) versus DVM biomass measured during all other years for the same calendar month (y-axis).

9) Extended Data Figure 9: Average diel cycles in $b b p$ from Kheireddine and Antoine ${ }^{19}$ for (blue line) mixing, (green line) oligotrophy, and (red line) declining conditions and (black line) the average of these three cycles, which corresponds to the diel cycle in Fig. 1b of the main manuscript. 

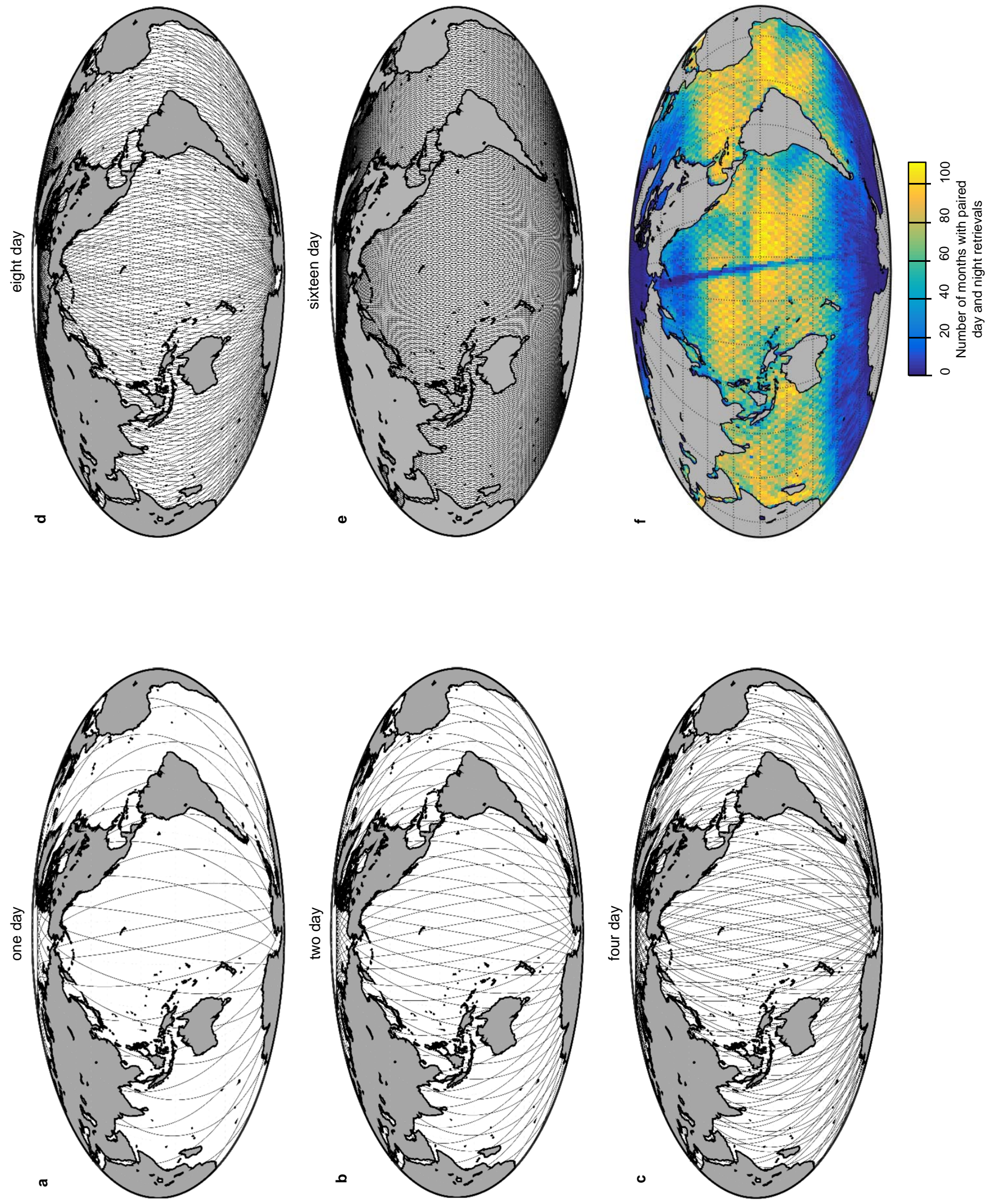
January

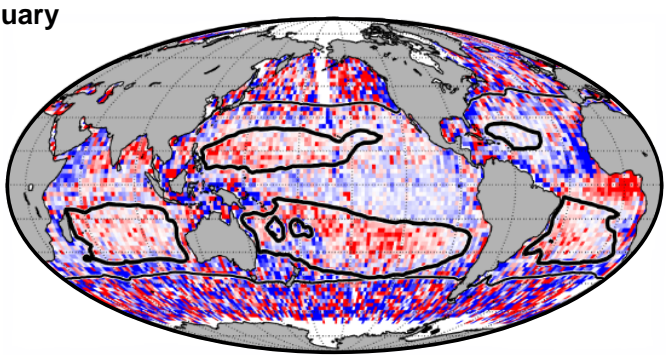

February

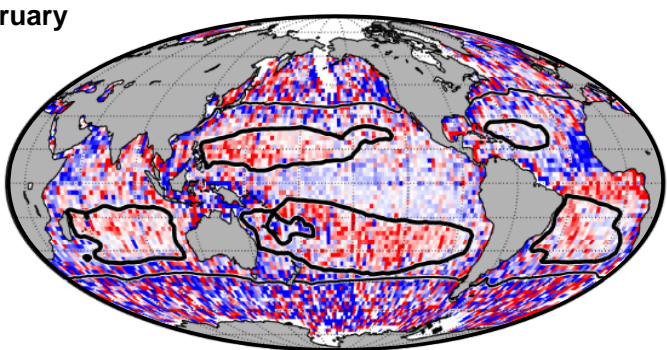

March

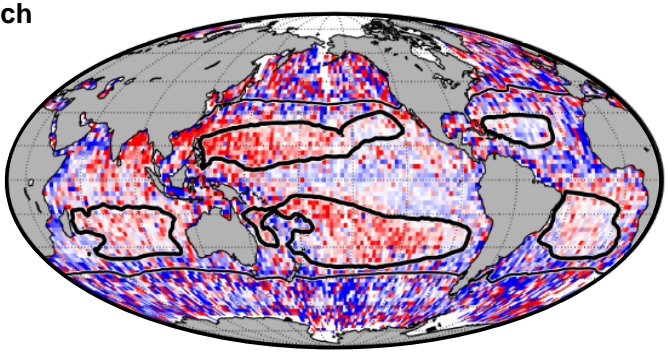

April

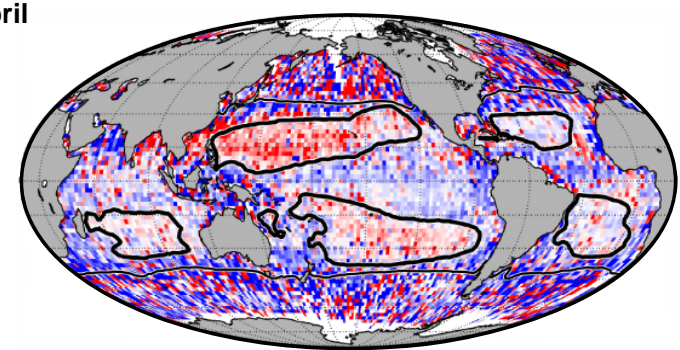

May

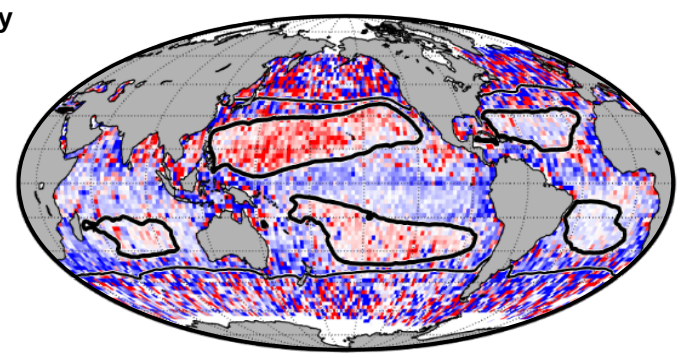

June

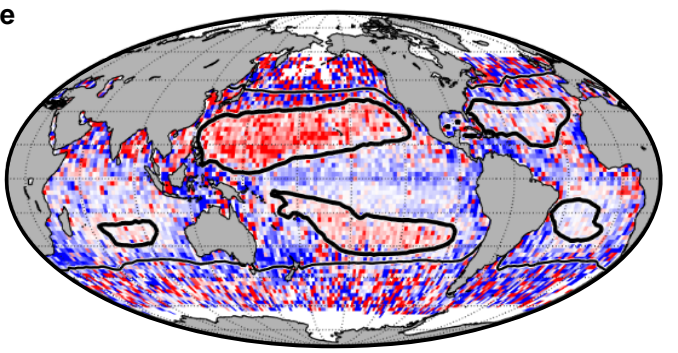

July

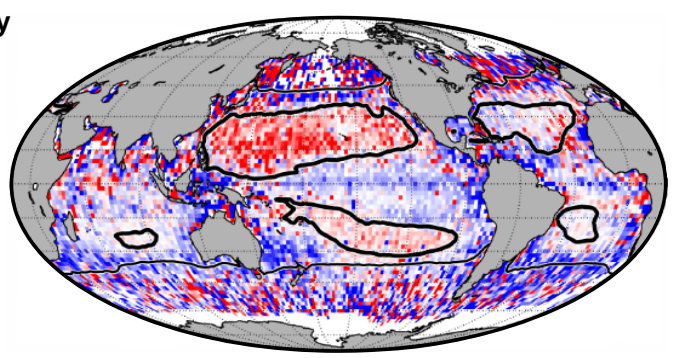

August

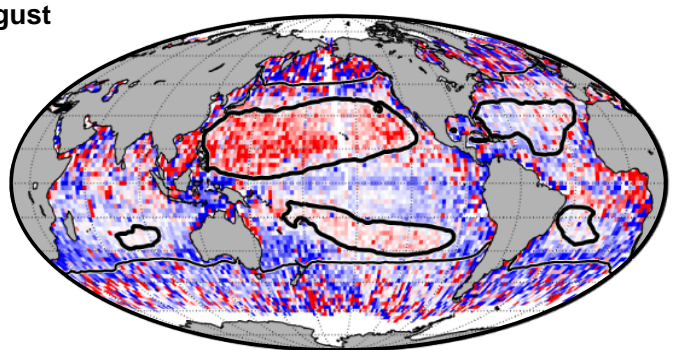

September

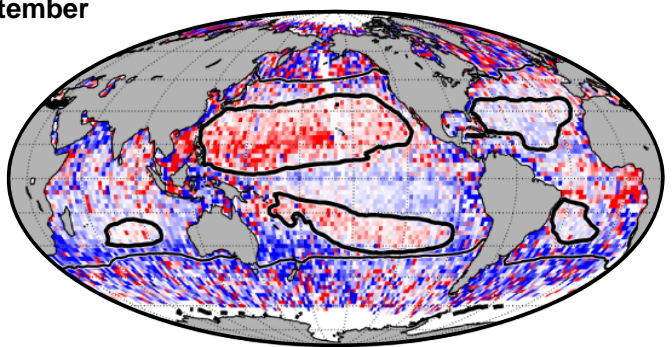

October

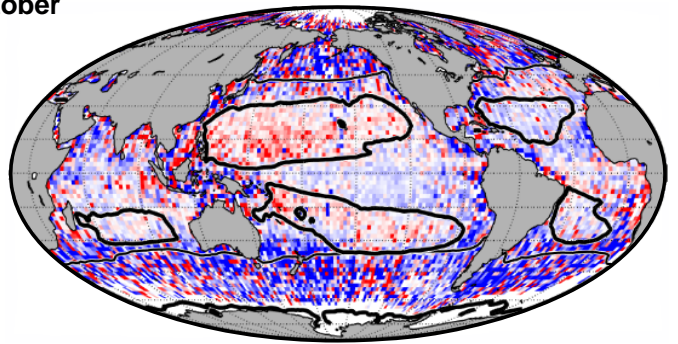

November

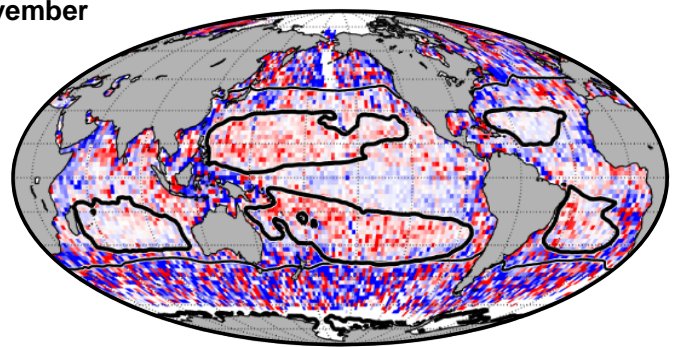

December

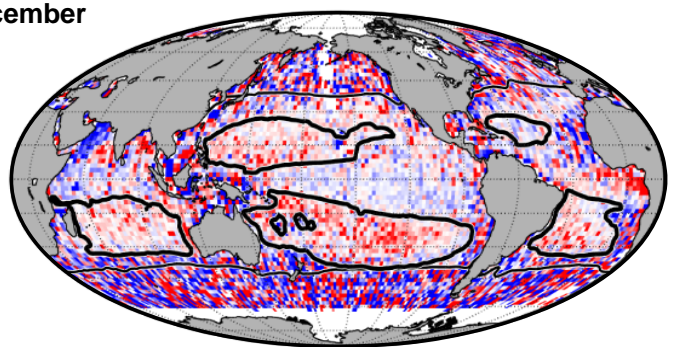

$\begin{array}{lllllllllll}-10 & -8 & -6 & -4 & -2 & 0 & 2 & 4 & 6 & 8 & 10\end{array}$

$\Delta b b p(\%)$ 
North Pacific Subtropical Gyre (NPSG)
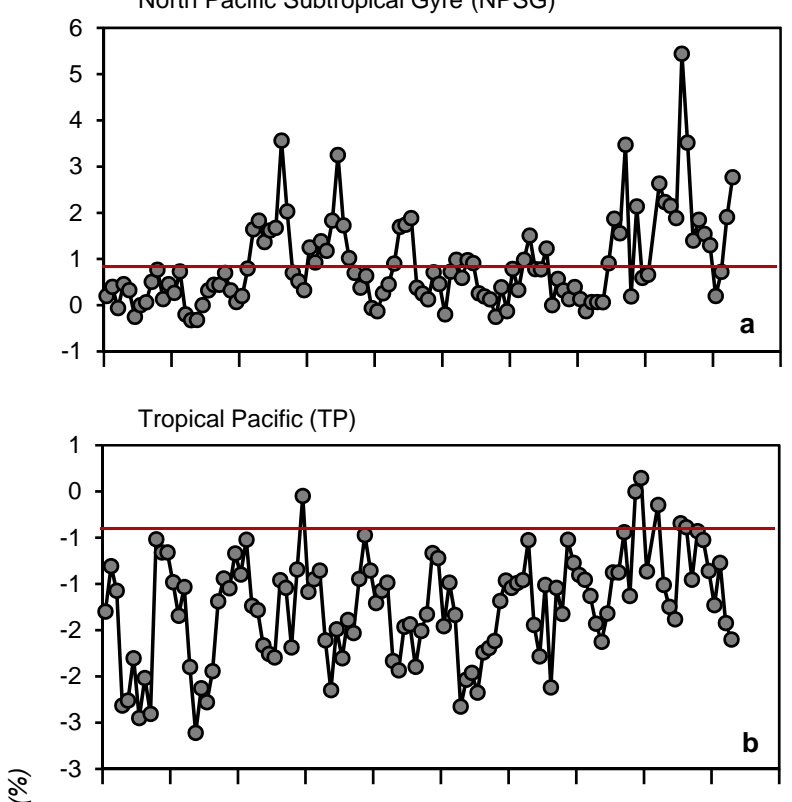

South Pacific Subtropical Gyre (SPSG)
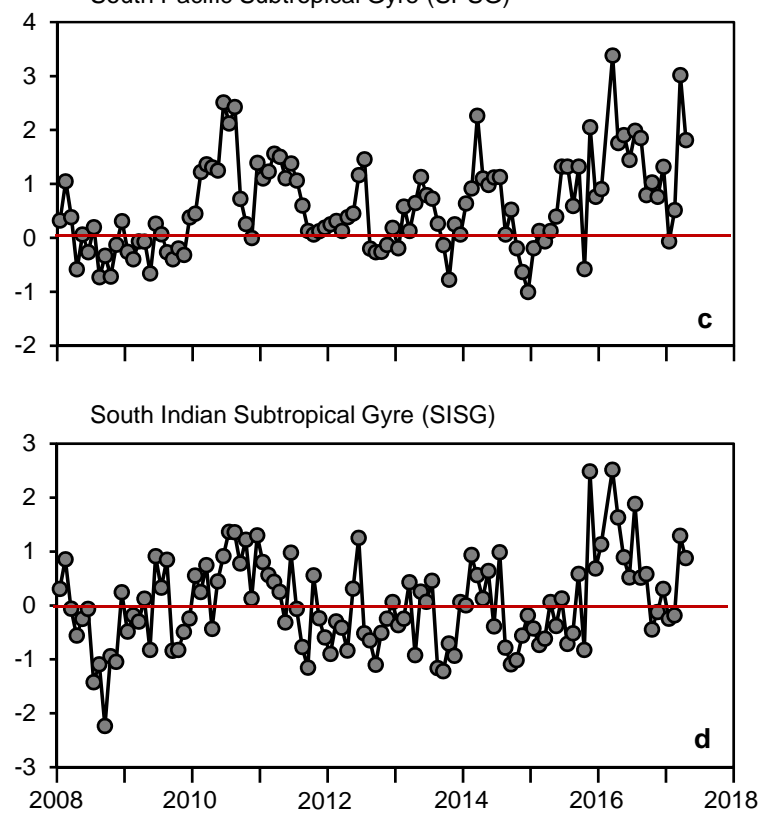
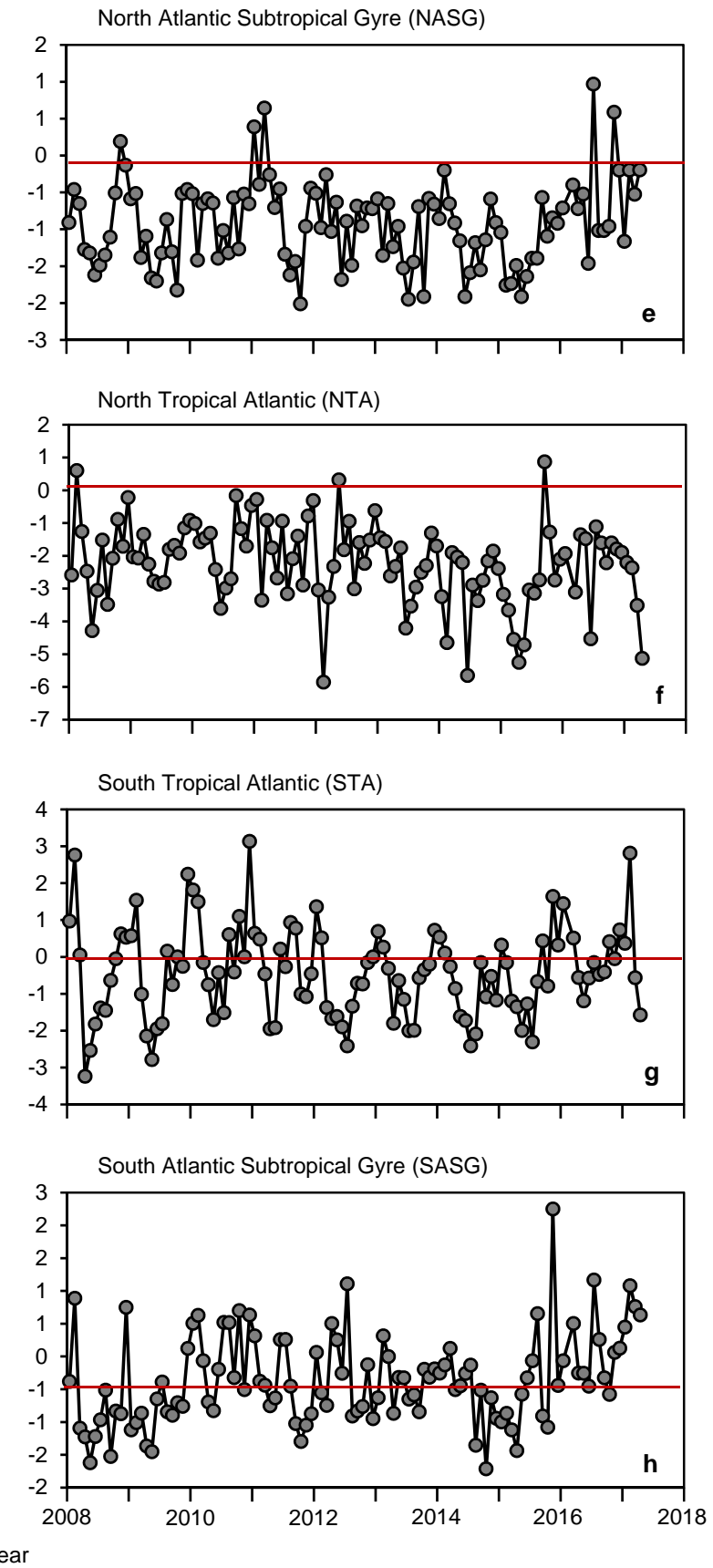


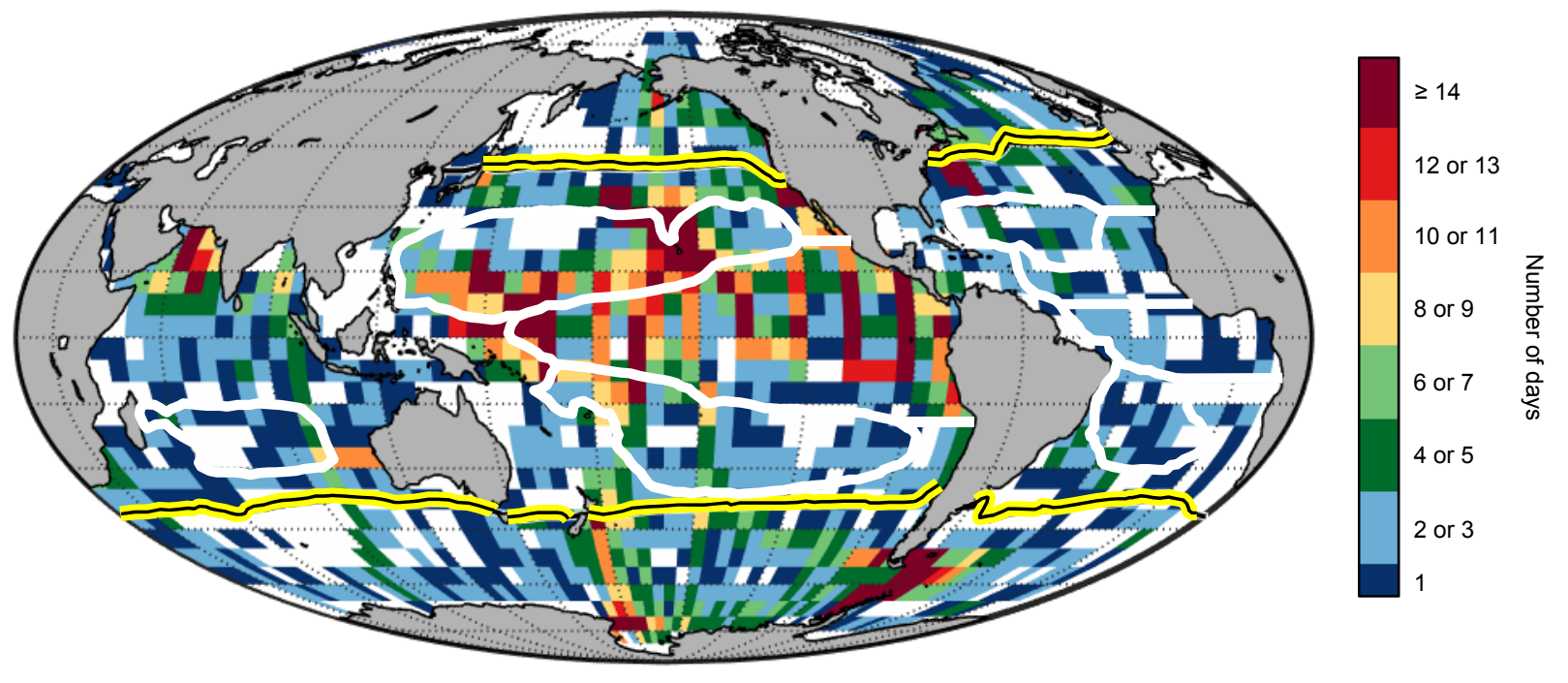



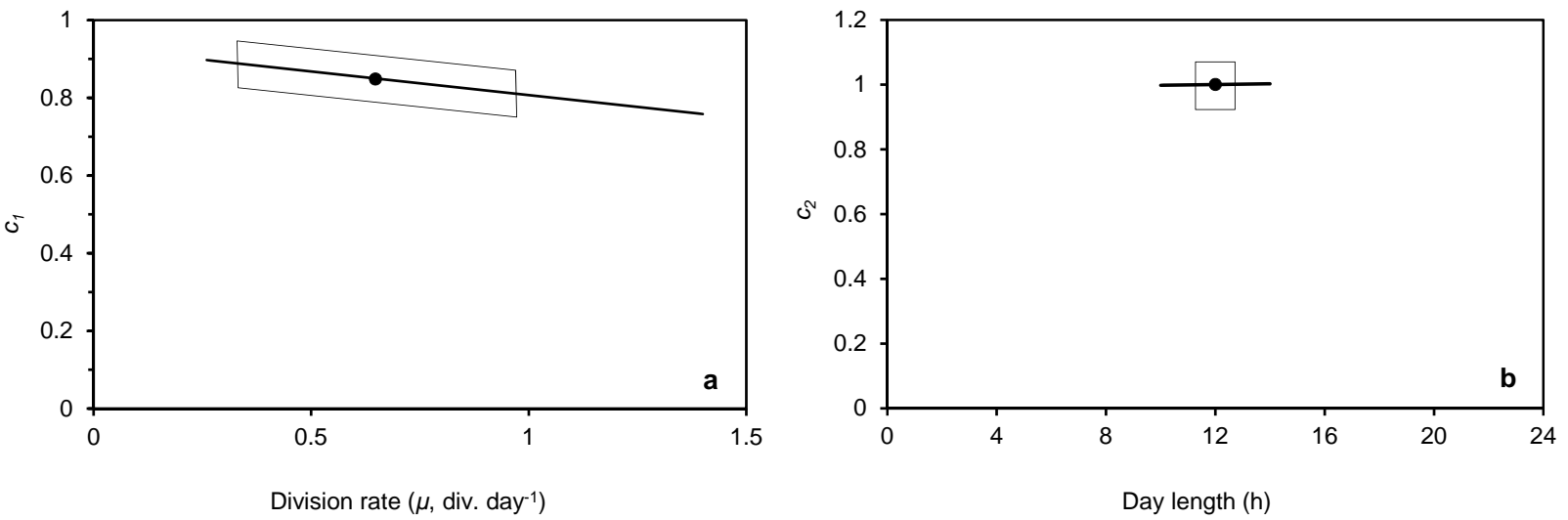

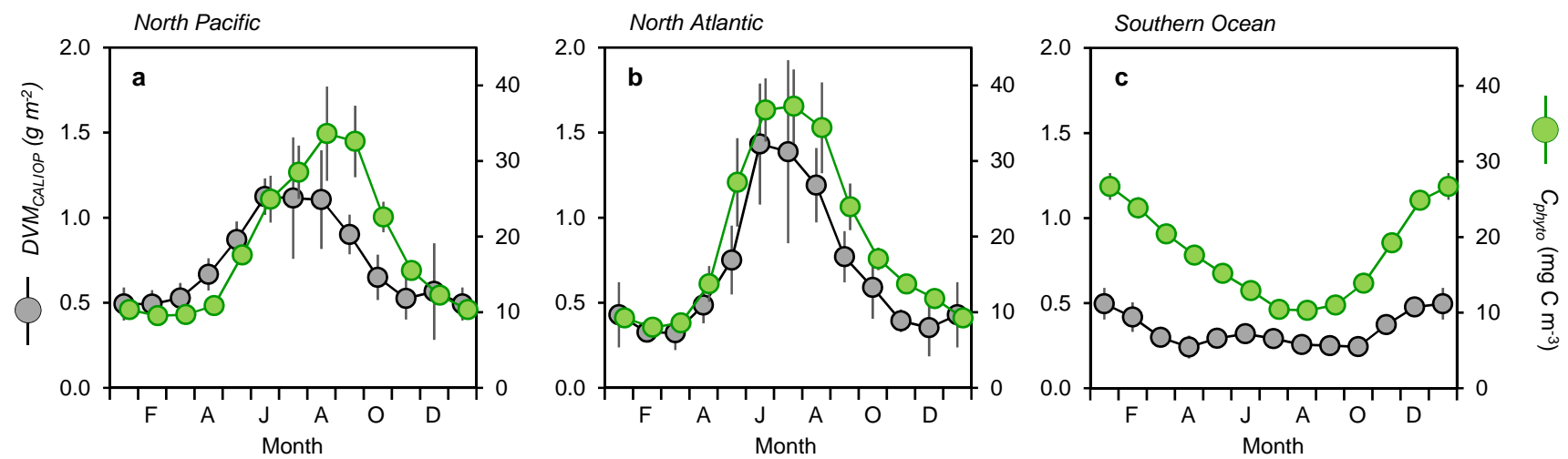


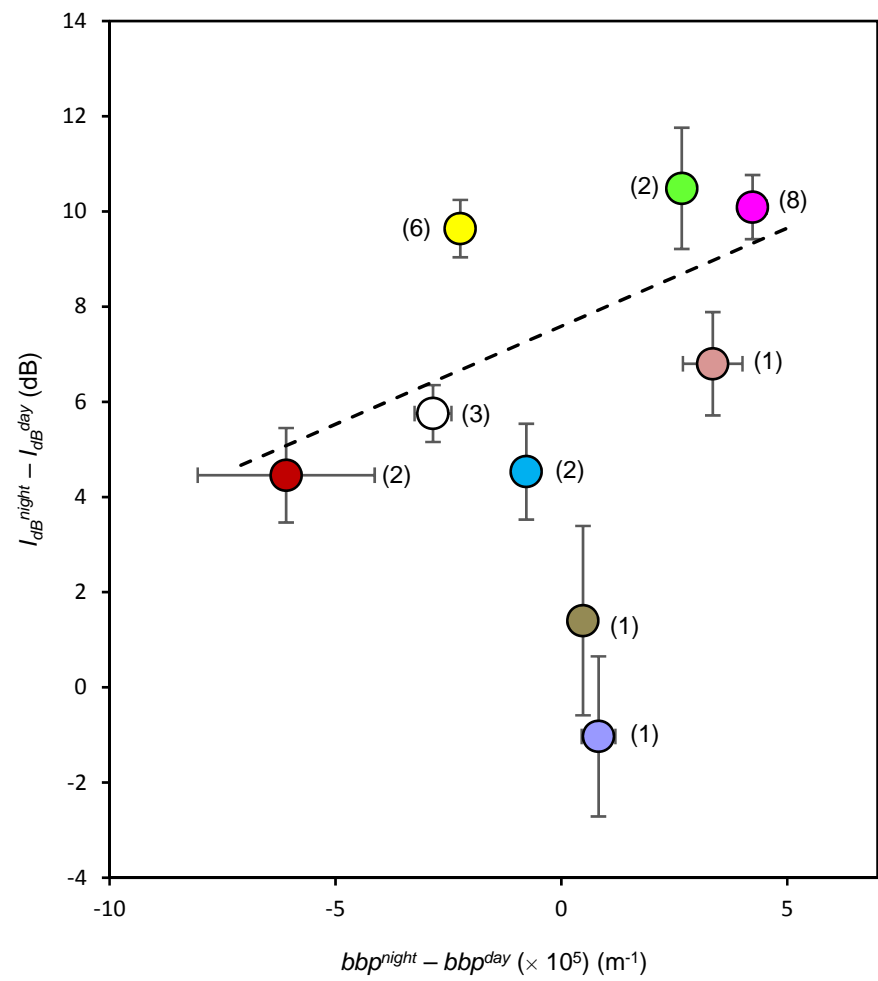

South Pacific Subtropical Gyre (SPSG)

North Pacific Subtropical Gyre (NPSG)

$\bigcirc$ Tropical Pacific (TP)

South Tropical Atlantic (STA)

North Atlantic Subtropical Gyre (NASG)

North Tropical Atlantic (NTA)

South Indian Subtropical Gyre (SISG)

South Atlantic Subtropical Gyre (SASG)

All other PSO areas 


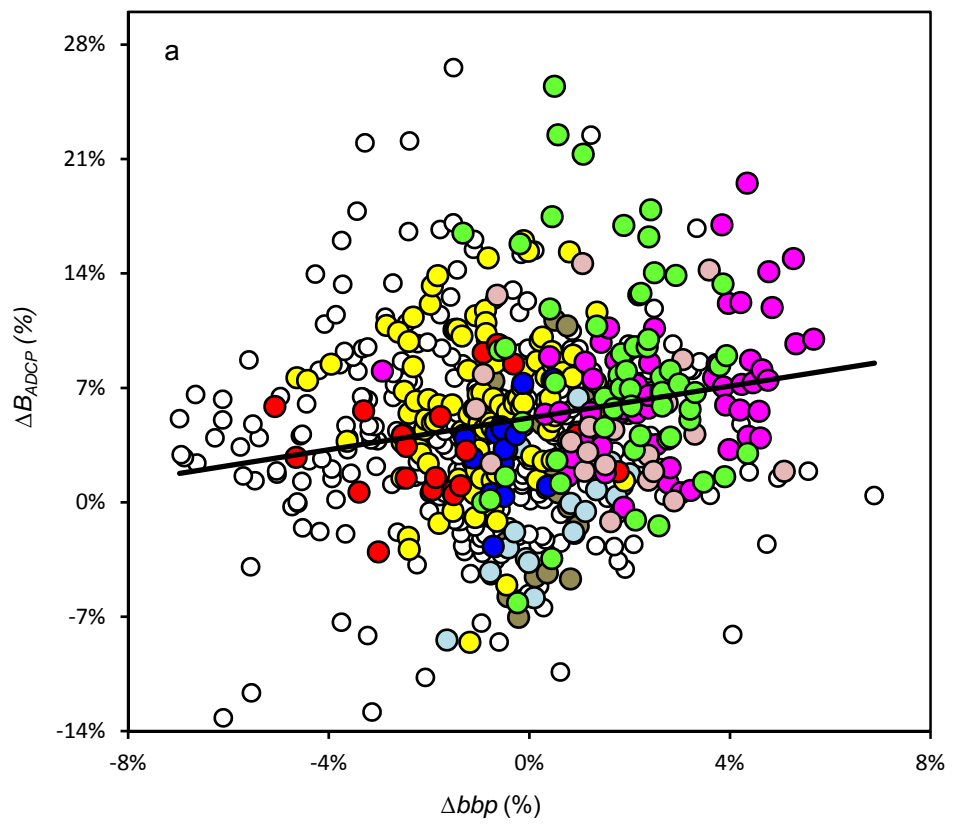

South Pacific Subtropical Gyre (SPSG)

North Pacific Subtropical Gyre (NPSG)

Tropical Pacific (TP)

South Tropical Atlantic (STA)

North Atlantic Subtropical Gyre (NASG)

North Tropical Atlantic (NTA)

South Indian Subtropical Gyre (SISG)

South Atlantic Subtropical Gyre (SASG)

All other PSO areas

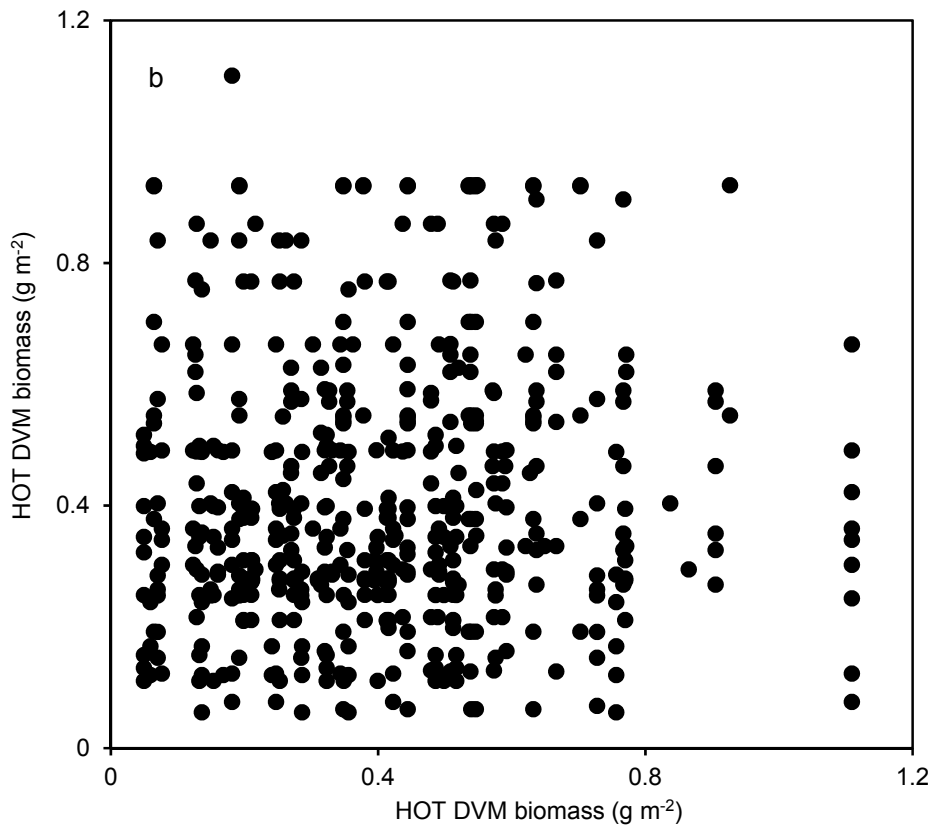




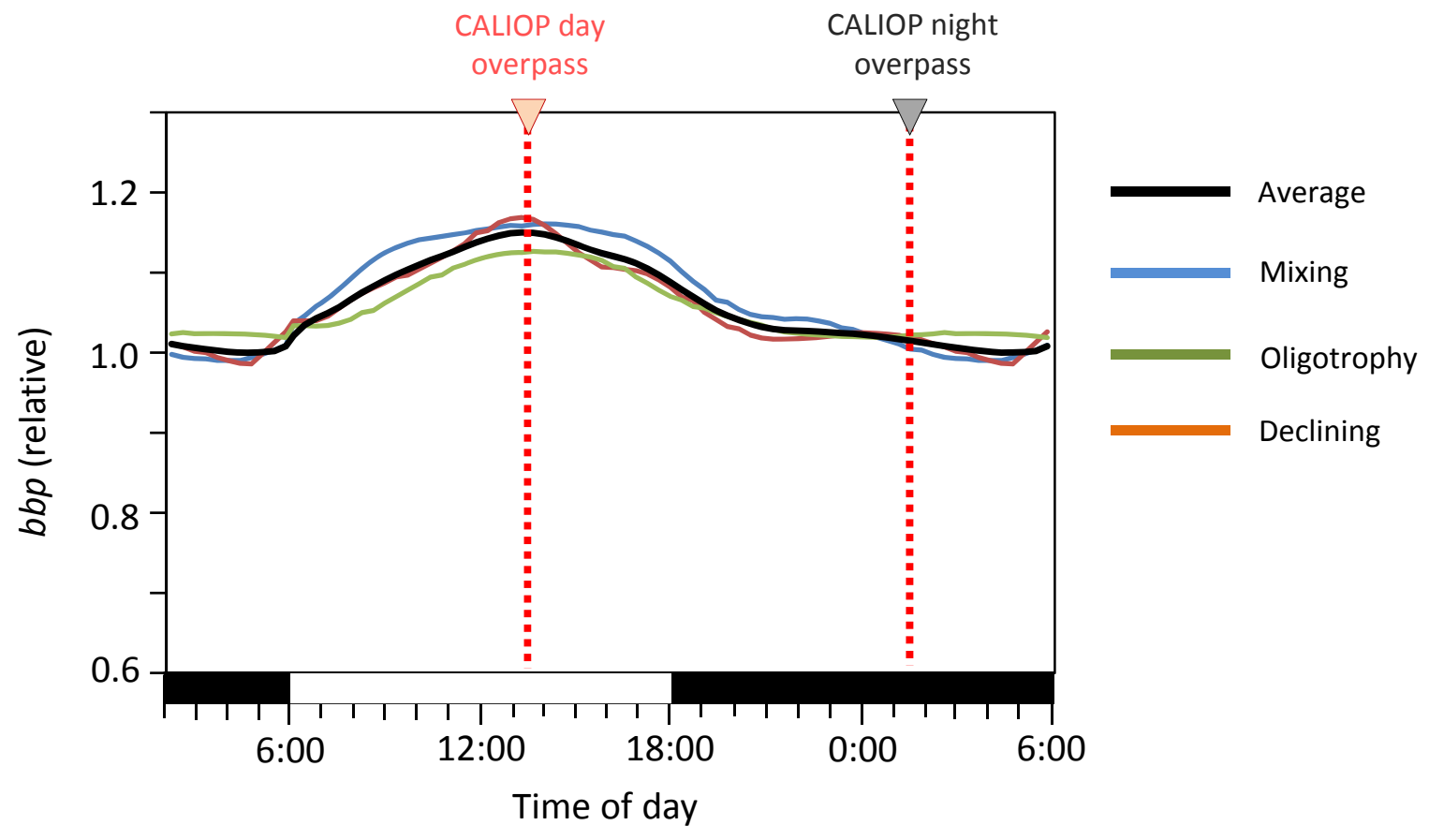

